\title{
The Tri-Lobed Disc in the Tomb of Sabu and the Basins at the Sun Temple Were for Beer
}

\author{
Akio Kato \\ Department of Mathematics and Physics, Faculty of Science, Kanagawa University, Hiratsuka, Japan \\ Email: akiokato1521@gmail.com
}

How to cite this paper: Kato, A. (2022). The Tri-Lobed Disc in the Tomb of Sabu and the Basins at the Sun Temple Were for Beer. Archaeological Discovery, 10, 35-59. https://doi.org/10.4236/ad.2022.101002

Received: November 7, 2021

Accepted: January 2, 2022

Published: January 5, 2022

Copyright $\odot 2022$ by author(s) and Scientific Research Publishing Inc. This work is licensed under the Creative Commons Attribution International License (CC BY 4.0).

http://creativecommons.org/licenses/by/4.0/ (c) (i) Open Access

\begin{abstract}
We propose that the Tri-Lobed Disc excavated from the Tomb of Prince Sabu (about 3000 BC, First Dynasty) was used in brewing beer as a mash rake to mix and even out the mixture of grains and hot water in a fairly big mash tun. Two observations which support this idea are presented in Section 1, and why the Disc works efficiently in mashing is explained in Section 2. We also propose in Section 3 our idea about how the Tri-Lobed Disc was made, and actually made its metal model to experiment and observe the flow around the Disc. About a would-be big "royal" mash tun of Prince Sabu is discussed in Section 4, and as a by-product of searching for any remains of ancient Egyptian mash tuns, we uncover in Section 5 that the large basins at the Sun Temple of Nyuserre (about 2400 BC, Fifth Dynasty) were such remains for ritual beer brewing. This reinterpretation succeeds in explaining almost all of their functions.
\end{abstract}

\section{Keywords}

Brewing, Mashing, Malt, Wort, Coandă Effect

\section{Introduction}

The disc-shaped artefact, aka the Egyptian Tri-Lobed Disc Figure 1, was excavated from the Mastaba of Prince Sabu (son of Pharaoh Anedjib, First Dynasty (c.3150-2890 BC)) by Walter Bryan Emery in 1936 (Emery, 1949). It has the structure of a central hub and three smoothly curved "lobes," and its dimensions are: $61 \mathrm{~cm}$ in diameter, $1 \mathrm{~cm}$ thick, and $10.6 \mathrm{~cm}$ in the center (see Figure 2 and Figure 3). The central hub obviously has been designed to fit onto a pole. It is reported that the object is made of schist, a very fragile and delicate rock. These features of the Disc, the curvature and delicacy, naturally suggest that it was used softly in some liquid. Taking account of these features of the Disc, and also of 


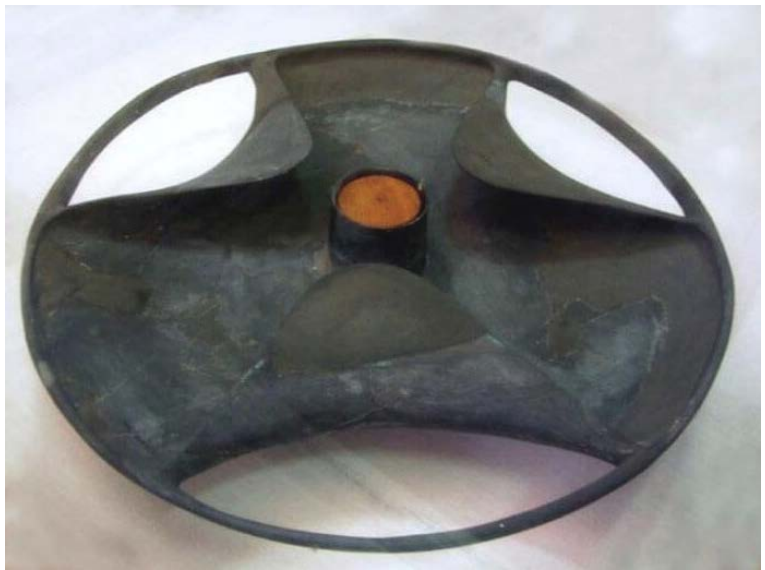

Figure 1. The Tri-Lobed Disc displayed in Cairo Museum, with dimensions: $61 \mathrm{~cm}$ in diameter, and $1 \mathrm{~cm}$ thick (http://ancients-bg.com/the-mysterious-sabu-disc/).

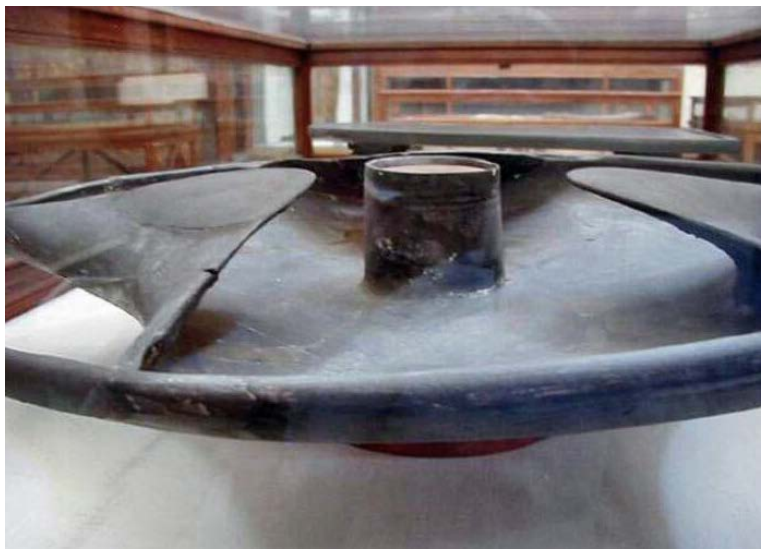

Figure 2. Lower angle view of the Tri-Lobed Disc (http://ancients-bg.com/the-mysterious-sabu-disc/).
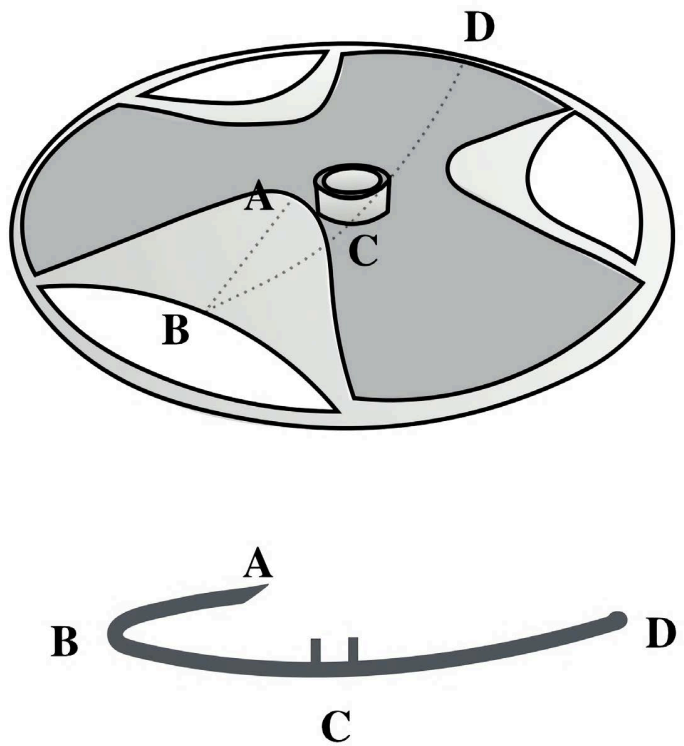

Figure 3. Tri-Lobed Disc illustrated (top), with its vertical cross section along $A B C D$ (bottom). 
the importance of beer as a votive object, we propose here a new hypothesis that the Disc was used in brewing beer:

The Tri-Lobed Disc was a mash rake, i.e., was used to mix and even out the mixture of grains and hot water in a fairly big mash tun.

We can point out two observations which support this idea. The first one comes from the burial chamber of Prince Sabu Figure 4. Here one can see votive objects consisting of stone or pottery vessels, flint or copper implements, ivory boxes, bones of two oxen and arrows; the fragments of the Tri-Lobed Disc is placed in the center of this chamber, described as "Fragments of metasiltstone bowl" (Emery, 1949). The character of these objects is that almost all of them are related to "foods" dedicated for the afterlife of Prince Sabu. Flint was effectively used to make a sickle in order to reap grain. ${ }^{1}$ Two oxen were needed for plowing as shown in the model Figure 5 . Therefore it would be quite natural to propose that the Disc was for the beer, which was one of the main "foods" (rather than "alcoholic drink") for ancient Egyptian, equally important as the bread, and also was important as an essential provision for their afterlife. Consequently, we can conclude that most of the pottery vessels in the chamber would be for beer and bread. (In ancient Egypt the making of bread and beer was closely related since basically the same kind of ingredients was used in both.) The solid shape of a beer jar with pointed base can be seen at the front of the model Figure $6^{2}$ of a bakery and brewery in Middle Kingdom, and this shape convinces us that the

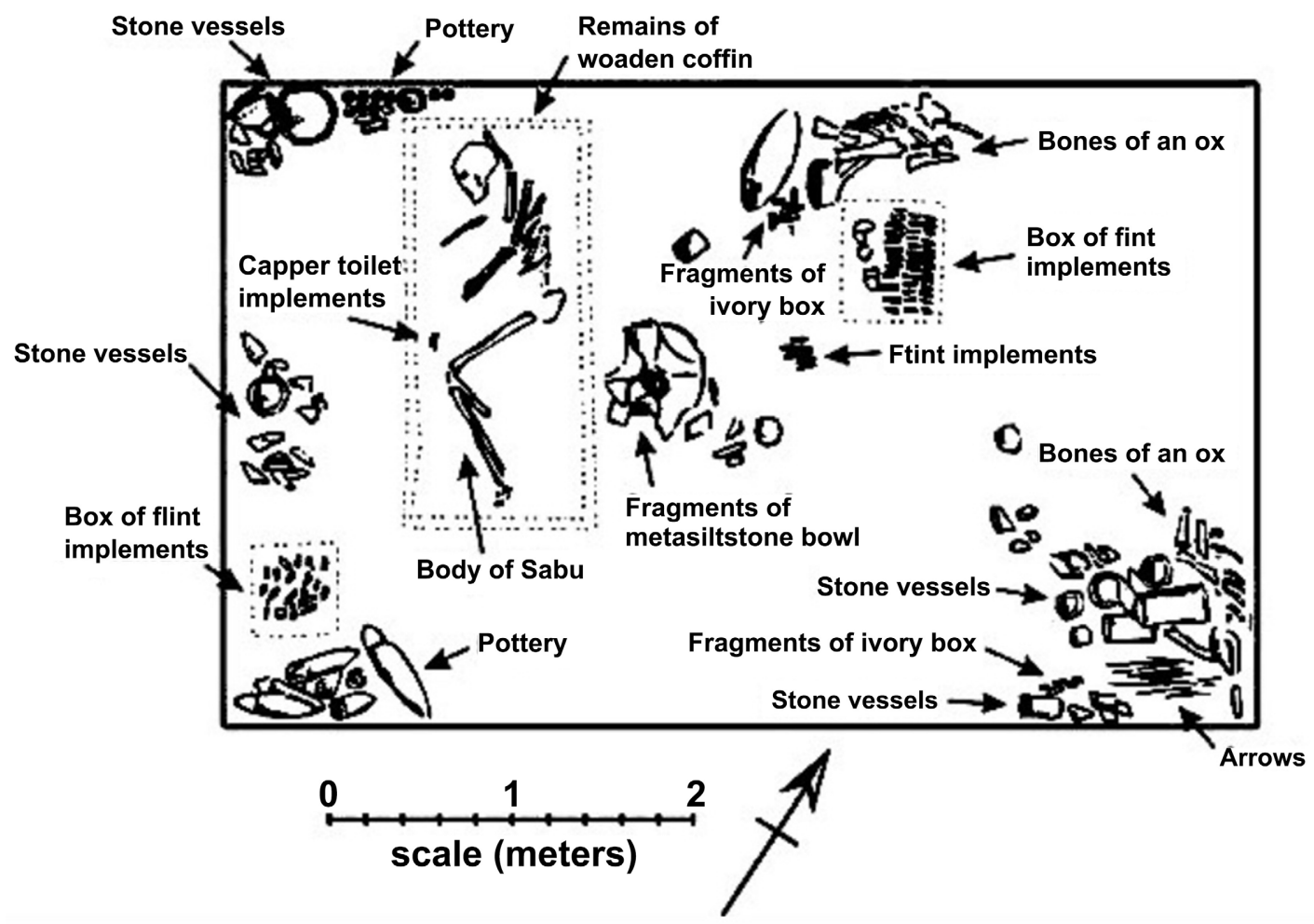

Figure 4. Burial Chamber of Sabu (Tomb 3111) in Saqqara (Emery, 1949).

${ }^{1}$ https://www.metmuseum.org/art/collection/search/557953

${ }^{2}$ https://collections.mfa.org/objects/143960/model-of-a-bakery-and-brewery 


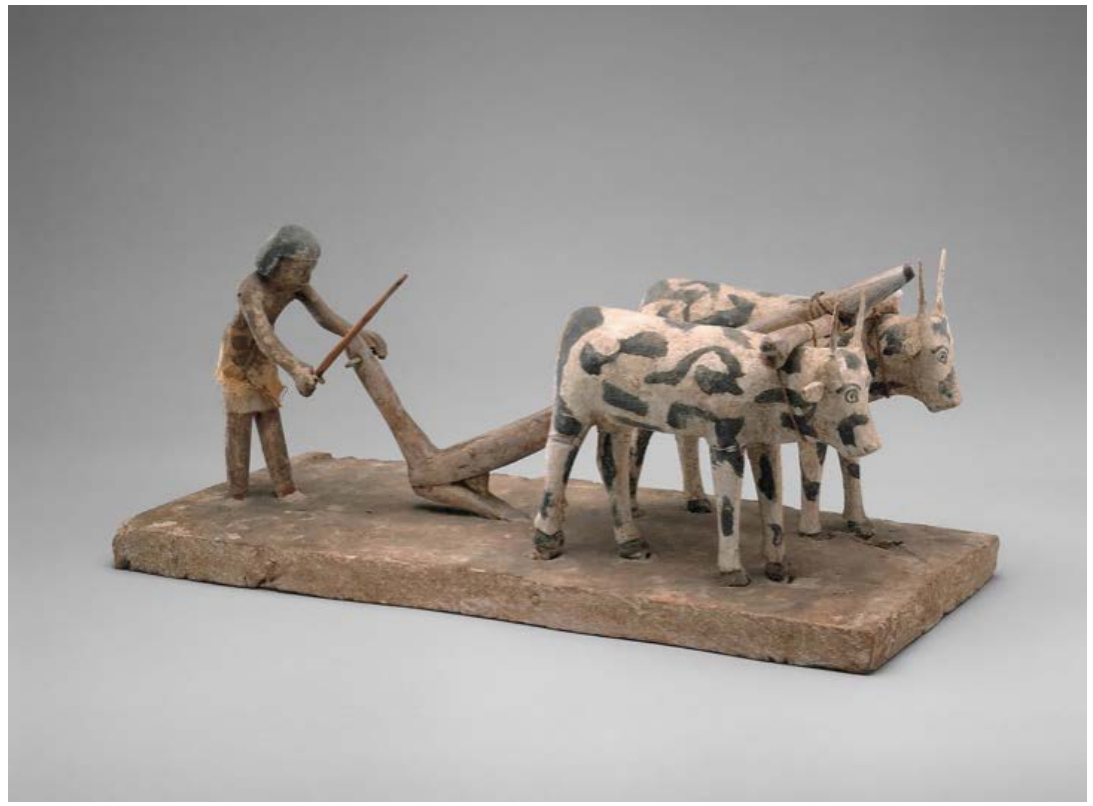

Figure 5. Model of a man plowing using the hook-shaped plow pulled by two oxen, Middle Kingdom (The MET, https://www.metmuseum.org/art/collection/search/544255).

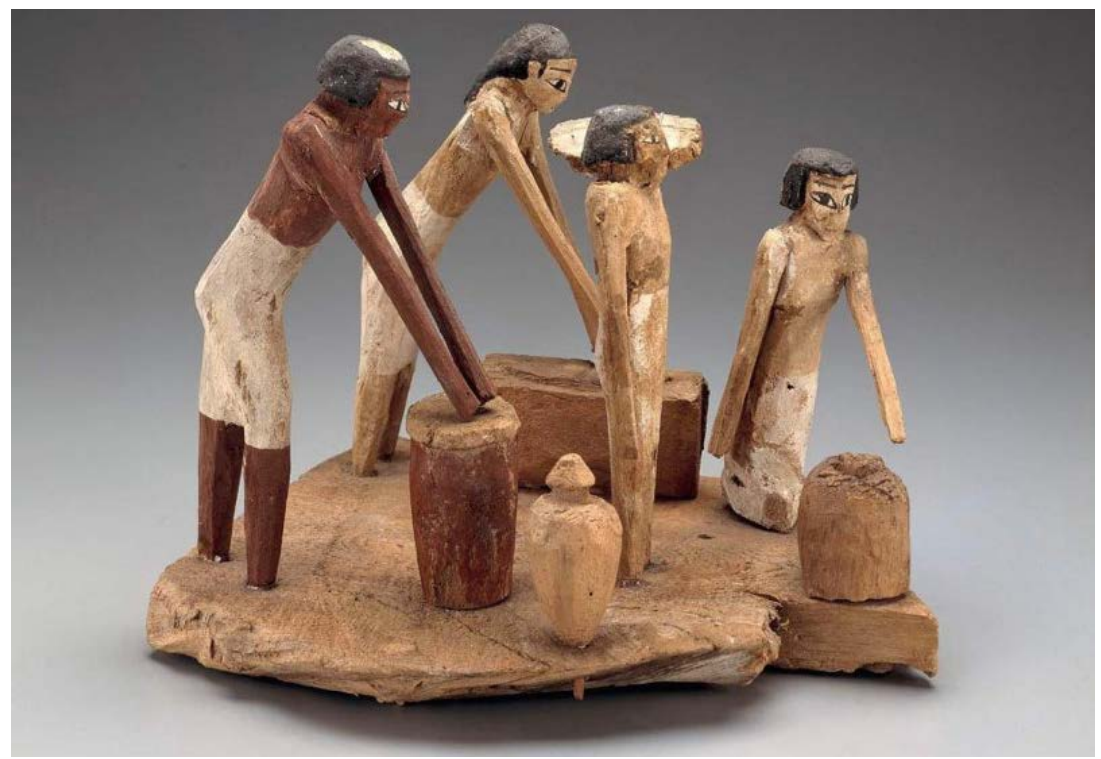

Figure 6. Model of a bakery and brewery excavated at Deir el-Bersha, Middle Kingdom (Boston Museum of Fine Arts).

potteries described at the bottom left of the burial chamber Figure 4 were for beer. Beer was produced in ancient Egypt since even before $5000 \mathrm{BC}$, and already around $3500 \mathrm{BC}$ it was produced in large scale and consumed in huge volumes. Figure 7, Figure 8 show remains of big beer vats excavated at the Hierakonpolis brewery, established around $3600 \mathrm{BC}$, the Predynastic era. A mixture of grains and water was heated gently in the vats (Farag, et al., 2019). Recent excavation (Bond, 2021) uncovered another large-scale brewery at the royal burial ground of Abydos Figure 9, Figure 10, dating back to the First Dynasty around 3000 


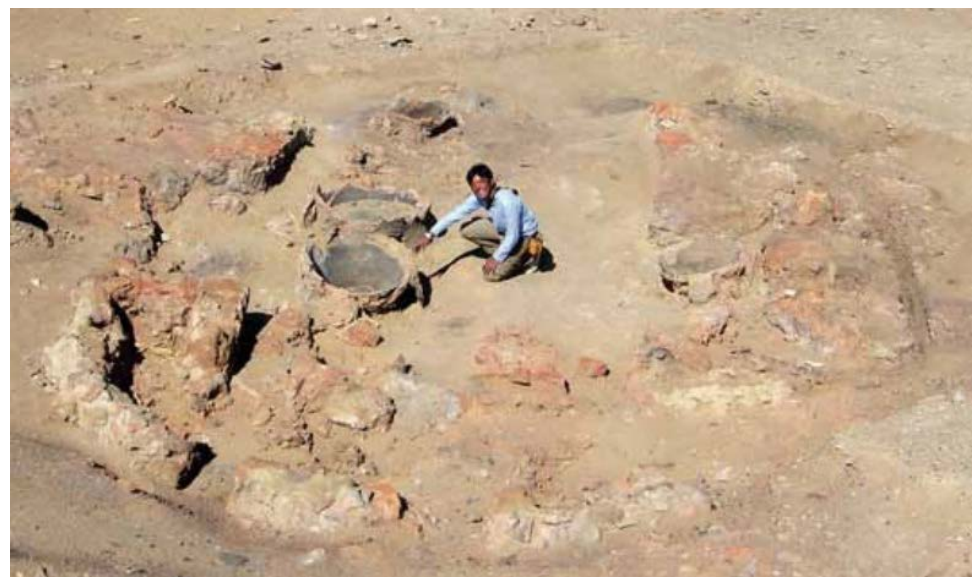

Figure 7. Brewery and pottery kiln installation at HK11, Hierakonpolis (Friedman, 2011), which dates back to around $3600 \mathrm{BC}$.

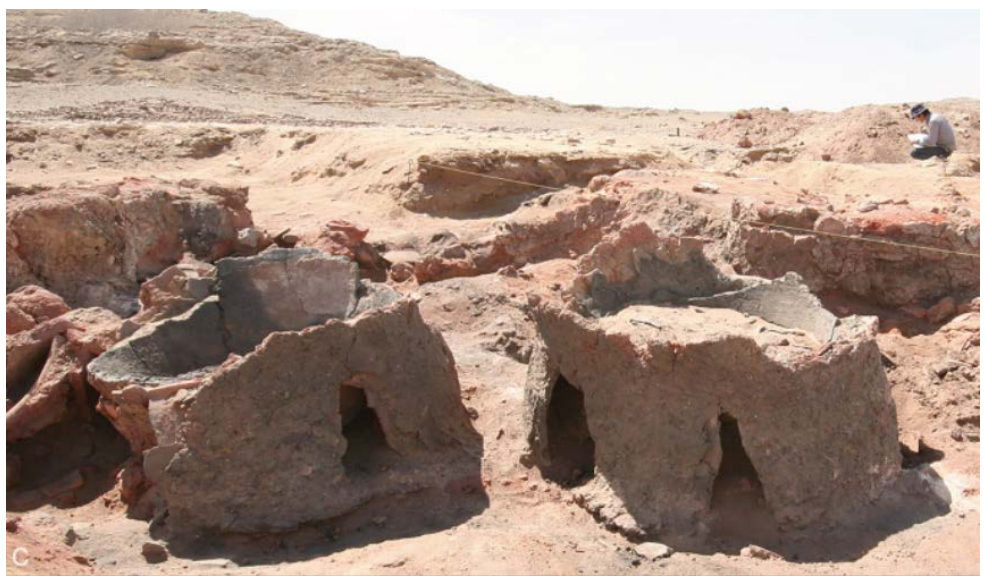

Figure 8. Detailed view of the two beer vats in Figure 7, standing between $40-60 \mathrm{cms}$ with diameters ranging from $60-85 \mathrm{cms}$

(https://www.nature.com/articles/s41598-019-52877-0.pdf).

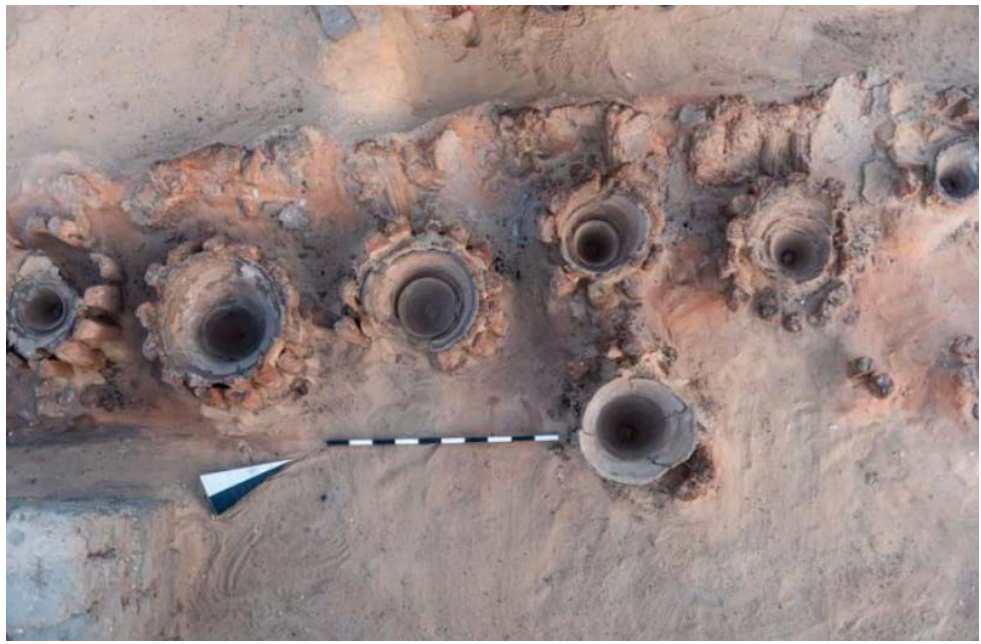

Figure 9. Heating/brewing installation at the royal burial ground of Abydos, which dates back to around 3000 BC (photo provided by the Egyptian Antiquities Ministry on Feb. 13, 2021) (https://news.artnet.com/art-world/worlds-oldest-beer-brewery-egypt-1944234?). 


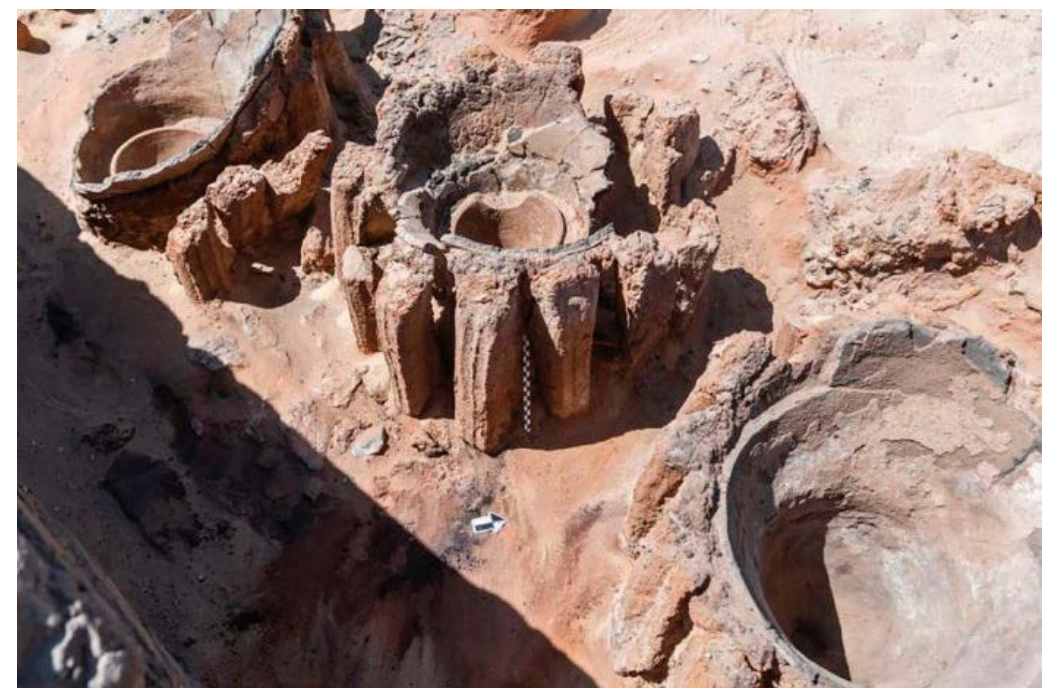

Figure 10. Detailed view of the vats in Figure 9 (photo provided by the Egyptian Antiquities Ministry on Feb. 13, 2021).

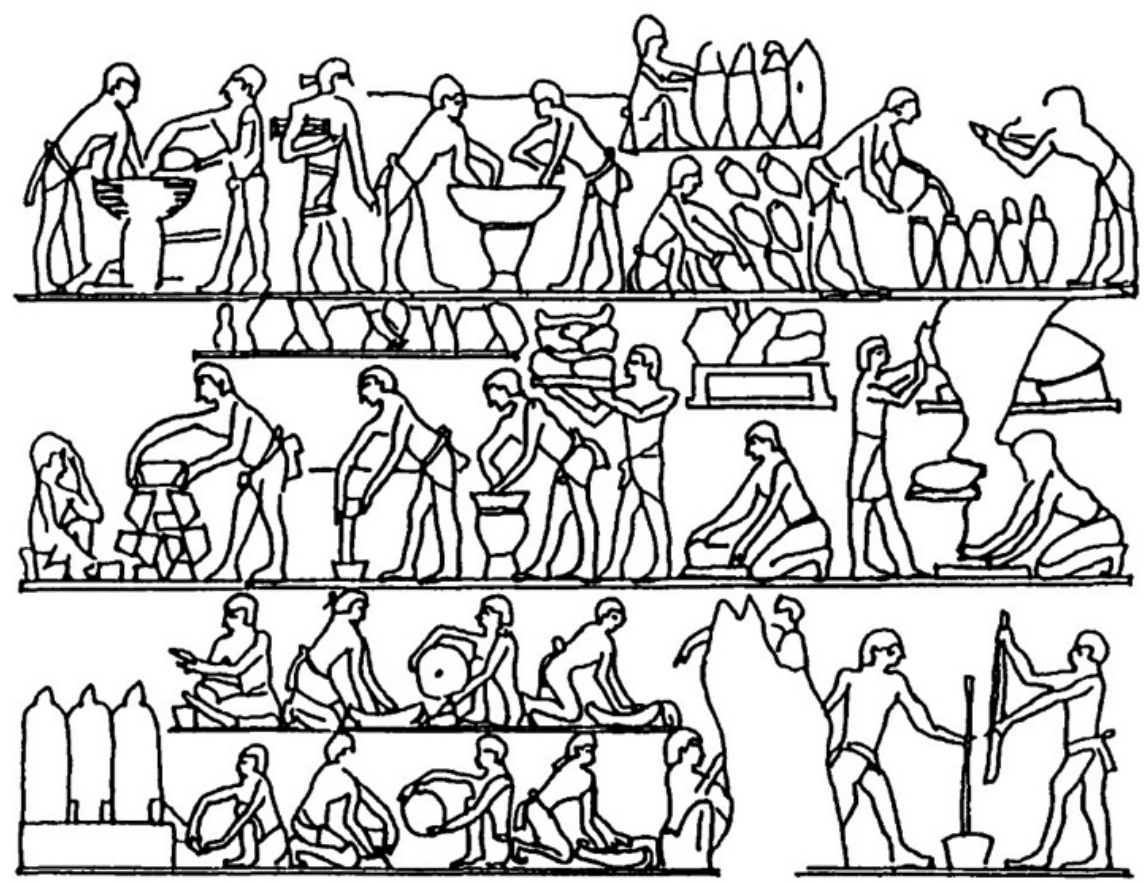

Figure 11. Relief from the Third Dynasty (2686-2613 BC) tomb of Ti at Saqqara depicting the beer-making process (Geller, 1992). Process is shown in sequence from bottom left to top right, from measurement of grain to filling and sealing jars of sieved beer. The scene in the middle of the top row would be mashing by bare hands.

BC, just the era of Prince Sabu. There were various grain treatments for making beer (Luoma, 2009), and in this article, we need to distinguish two methods of mashing: Unheated and heated. Figures 7-10 show the heated case, while the unheated way of mashing, using bare hands, is shown in the middle of the top row of the relief Figure 11. Bare hands only would be ineffective for mashing in a "big" tun and could not be used in case of heated mashing. Thus, some mash 
rakes become needed. We believe the Tri-Lobed Disc was used as a mash rake in an open-topped mash tun, a dedicated vessel for mashing (probably, heated), big enough to accept the Disc of diameter $61 \mathrm{~cm}$ : See Section 4 .

The second observation which supports our proposal is simply the color of the Disc. Its grey color works quite well in distinguishing the Disc from the brown-colored wort. Recall that the Disc was made around $3000 \mathrm{BC}$, the early Bronze Age, and most of metals in those days were copper or bronze. If it were made of copper or bronze, the resultant would be brown colored, making difficult to examine the quality of wort, scooped by the Disc Figure 16.

The outline of this article is as follows: In Section 2 we explain how the "Coandă effect" works efficiently in mashing, and in Section 3 we propose our idea about how the Tri-Lobed Disc was made. We discuss in Section 4 about a would-be big mash tun of Prince Sabu, and present in Section 5 our new view that the basins at the Sun Temple of Nyuserre were mash tuns for ritual beer brewing.

We hope this article can revive the importance of "ritual brewing" in the history of ancient Egypt, in particular in the third and fourth millennia BC.

\section{The Coandă Effect}

Let us show how the Tri-Lobed Disc works efficiently in mashing. An idealistic mixing of grains with hot water should be smooth without generating any vortices or bubbles, ensuring homogenous mash with uniform temperature distribution. The three smoothly curved lobes can induce such a smooth mixing due to the "Coandă effect" (named after Romanian aerodynamicist Henri Coandă (1885-1972)), a nature of liquid described as follows:

A fluid tends to follow a nearby curved surface if the curvature of the surface is not too sharp. Figure 12 shows how the liquid flows around the Disc when it is pressed downwards in a liquid, while Figure 13 presents the essential flow of the mixture of grains and water when the Disc is moved up and down; Figure 12 is the detailed version of (2) in Figure 13. In order to observe the role of lobes, suppose the Disc had lost them and consider the resulted disc with three holes of sharp edges. Then the flow of Figure 12 would turn into Figure 14 causing vortices or bubbles at the sharp edges, undesirable for uniform smooth mixing. Note also that the slightly rounded bottom of the Disc makes the Disc easy to be pressed down softly. Thus, as a whole, we can conclude that the Coandă effect would be generated as in Figure 12 and Figure 13, due to the rounded (neither flat nor sharp) parts of the surface of the Disc colored in purple in Figure 15, together with the rind at the circumference. We note another advantage of the slight roundness of the bottom is that the Disc can serve as a bowl to scoop and examine the wort, as in Figure 16. As mentioned before, the grey color of the Disc is helpful in such an examination, well contrasting with the brown color of wort.

Remark: The disc with holes, of the form like in Figure 14, could be rather used in wine making as a pigeage plate for "punching down" in an open-top 


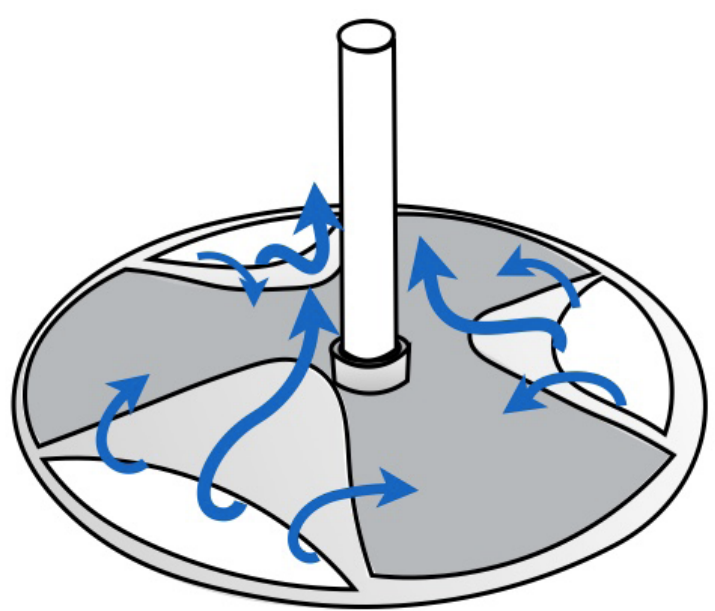

Figure 12. Flow around the Tri-Lobed Disc due to the Coandă effect, when it is pressed down in a liquid. The flow when the Disc is pulled up will be exhibited just by flipping all the arrows.

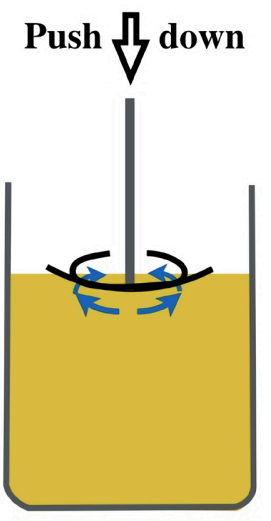

(1)

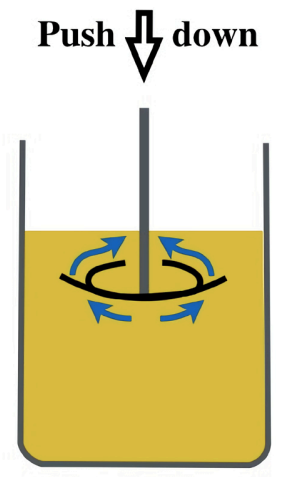

(2)

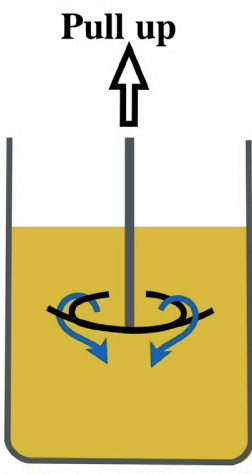

(3)

Figure 13. Flow around the Tri-Lobed Disc when it is softly moved up and down in a liquid.

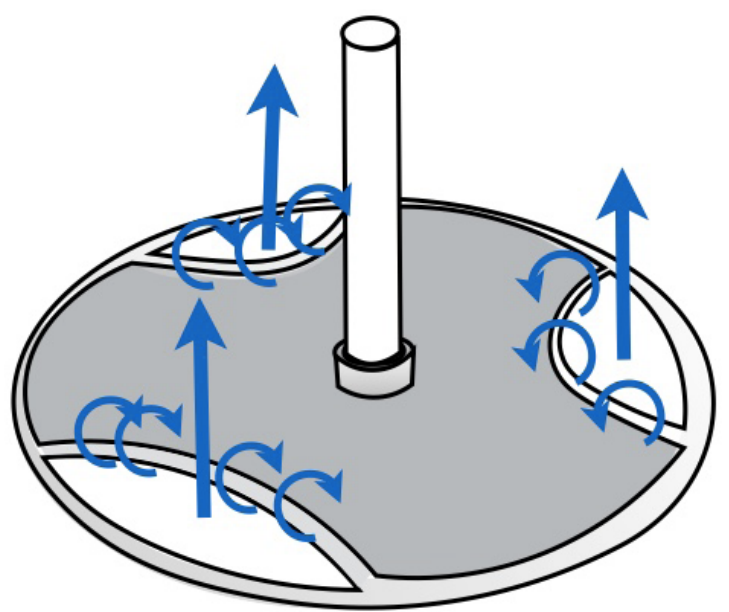

Figure 14. Flow around the disc with three holes, causing vortices or bubbles (described as small round arrows) at the sharp edges. 

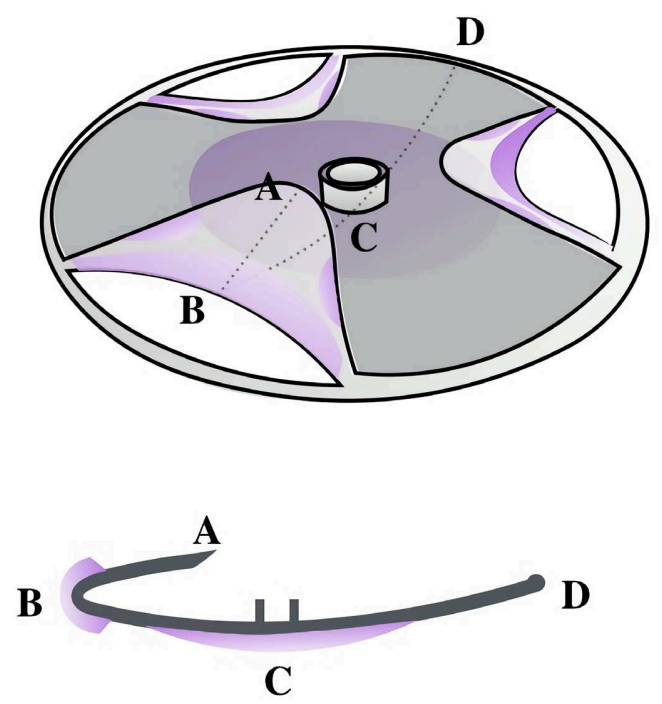

Figure 15. The rounded parts of the surface of the Disc, colored in purple, generate the Coandă effect as in Figure 12 and Figure 13.

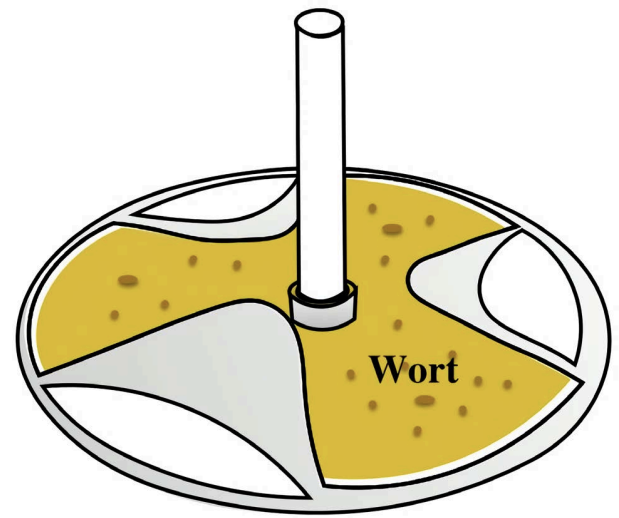

Figure 16. Wort, mixture of grains and hot water, scooped by the Tri-Lobed Disc.

fermenter. Note though that in the punch down one needs a strong force so that the disc should be made by some metal not by a fragile stone. Therefore, we can exclude the possibility that the Tri-Lobed Disc was used as a pigeage plate in wine making. About "punch down" see:

https://www.cawineclub.com/blog/all-about-punch-downs/.

\section{How the Tri-Lobed Disc Was Made}

Let us show our idea about how the Tri-Lobed Disc was made. Though it is reported that the Disc was made somehow by cutting the delicate stone called "schist," we believe that it was rather made by hands using viscous materials like gypsum containing some clay, and later sun-dried. The actual process could be two steps: First, make a platter utilizing such materials, and in order to make lobes, cut and bend it as in Figure 17. The resultant lobes are a bit short, so the next step is to attach fins to extend them as in Figure 18. This kind of "folding" technique can be seen in the artefacts Figure 19 in the Third and Fourth Dynasties, 


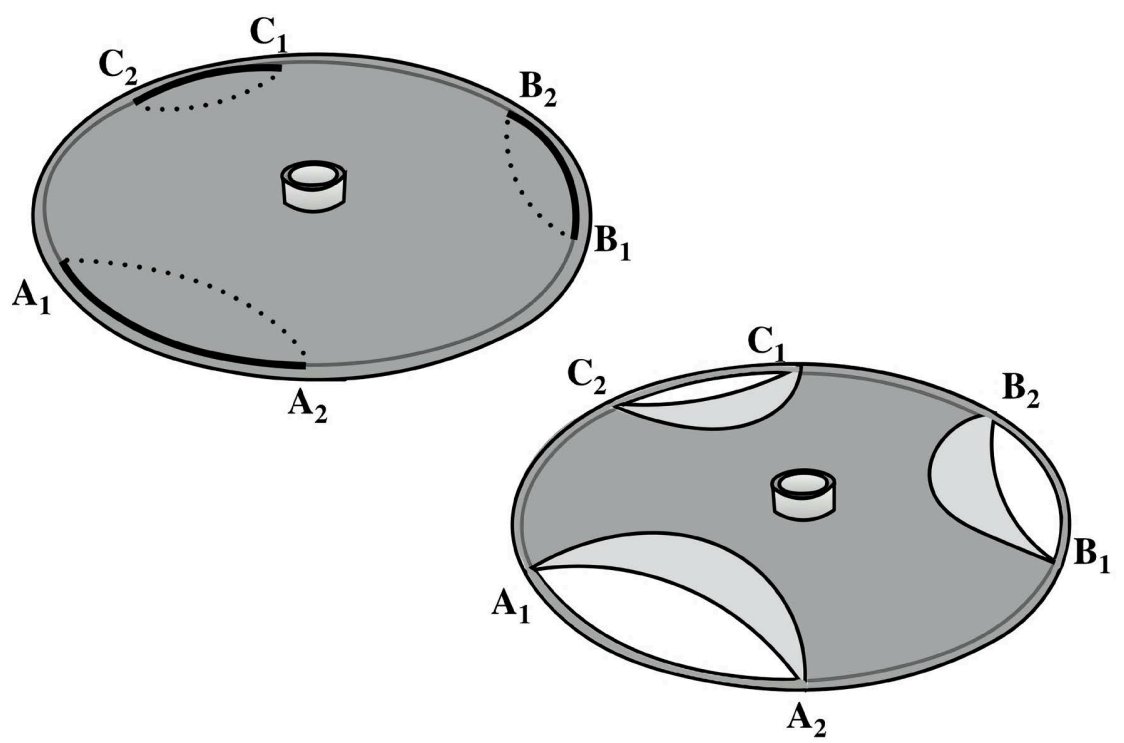

Figure 17. The first step to make the Tri-Lobed Disc: Cut the platter along the bold black curves and then bend along the dotted black curves (top left) to get a tri-lobed disc with short lobes (bottom right).

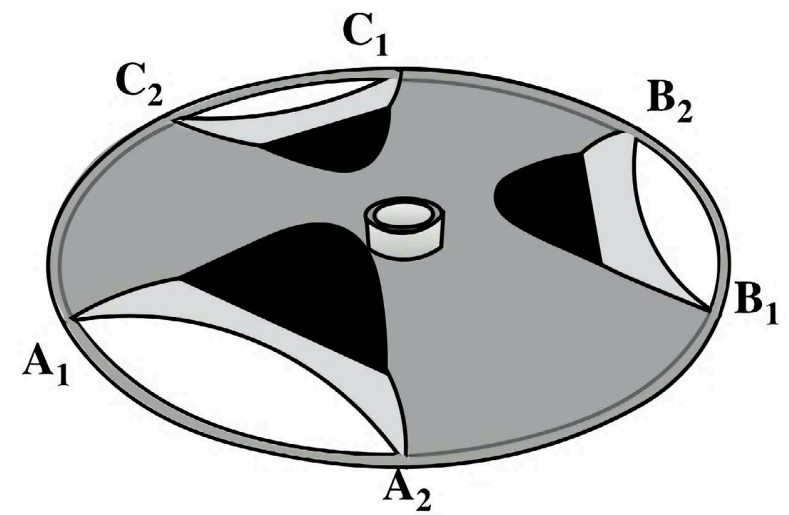

Figure 18. The second step to make the Tri-Lobed Disc: Extend lobes by attaching "fins" (colored black).
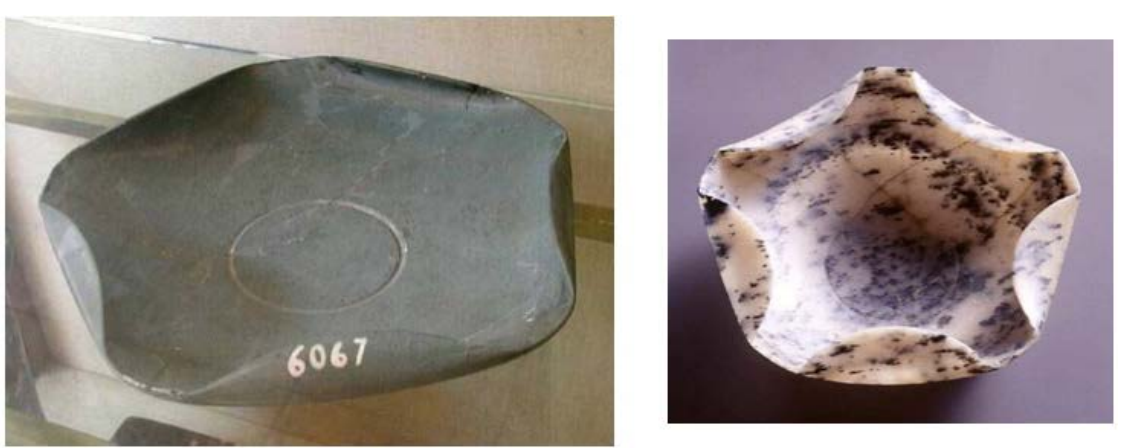

Figure 19. Stone bowls with folded corners, from Saqqara. (Left): Schist (slate) bowl with diameter $38 \mathrm{~cm}$, Third Dynasty (http://www.ancient-wisdom.com/egyptxtremasonry.htm). (Right): Gneiss bowl with diameter $20 \mathrm{~cm}$, Fourth Dynasty or earlier. (Catalogue No. 99 in https://www.almendron.com/artehistoria/arte/culturas/egyptian-art-in-age-of-the-pyrami ds/catalogue-fourth-dynasty/8/) 
and it is known that "patching or weaving" technique was widely used in ancient Egypt in particular when larger pottery vessels were made. ${ }^{3}$ Of course, after this hand-shaping the resulting product should be well sun-dried. The reason the three arc edges $A_{1} A_{2}, B_{1} B_{2}, C_{1} C_{2}$ were remained would be to reinforce the whole structure, and for further reinforcement, we believe, the pole and the rim of the Disc were tied with strings as in Figure 20 (such an idea can be seen also in (Vashakidze, 2016)).

We may claim that the Disc was hand-made not using a machine like the potter's wheel because its edge-on view is a bit asymmetric as seen in Figure 2; more precise picture can be seen in (Solenhofen, 2003). About material, we imagine that a pottery or terracotta of the form of the Tri-Lobed Disc could be made even if we use only the Nile or Marl clay. But its color should not resemble the brown color of the wort as pointed out in Section 1, so we believe that they intentionally used some gypsum or silt in order to make the resulting Disc be grey-colored. It is known that, in stone-vessel making, ancient Egyptian in the Early Dynastic Period had tried practically every type of hard stone available in stone-rich Egypt. ${ }^{4}$

Though we needed to experiment with the above method, we have felt that some delicate skill or some experience of making pottery would be needed to realize the Disc in case some kind of gypsum or clay were used. So, we chose an easier way to use the metal of aluminium which is easy to be cut and bent, and made a "metal" model of the Tri-Lobed Disc as in Figure 21. What we actually used was a lid of cooking pot made of aluminium, already of the form of platter so that we could instantly apply the method of Figure 17 and Figure 18. Note that this model of small diameter about $30 \mathrm{~cm}$ is strong enough in its structure so that it needs no reinforcement by strings as in Figure 20. Moving this metal disc in water, we could confirm the flow around the disc as described in Figure 12 and Figure 13 (see the next "Remark"), and found the following new facts:

1) The metal tri-lobed disc floats on the surface of water. Though the stone-made Tri-Lobed Disc Figure 1 is surely heavier than the metal one, it has much wider rounded bottom. So we believe it would also float on the surface of wort with high density.

2) We don't need strong power in moving the disc softly up or down in water. What we need is a slightest force to induce the flow of water; then, the flow itself helps to move the disc. (In spite of this fact, the whole disc itself, having a wide surface, would receive some strong pressure from the liquid so that some reinforcement as in Figure 20 would be necessary in particular when the disc is big.)

3) Longer lobes can "grab" and move more water; that is the role of fins in Figure 18 or Figure 21.

Remark about the validity of the experiment. In fluid dynamics, flow pattern is known to be essentially determined by the Reynolds number. More precisely:

${ }^{3}$ https://en.wikipedia.org/wiki/Ancient_Egyptian_pottery

${ }^{4}$ https://www.almendron.com/artehistoria/arte/culturas/egyptian-art-in-age-of-the-pyramids/stonevessels-luxury-items-with-manifold-implications/ 


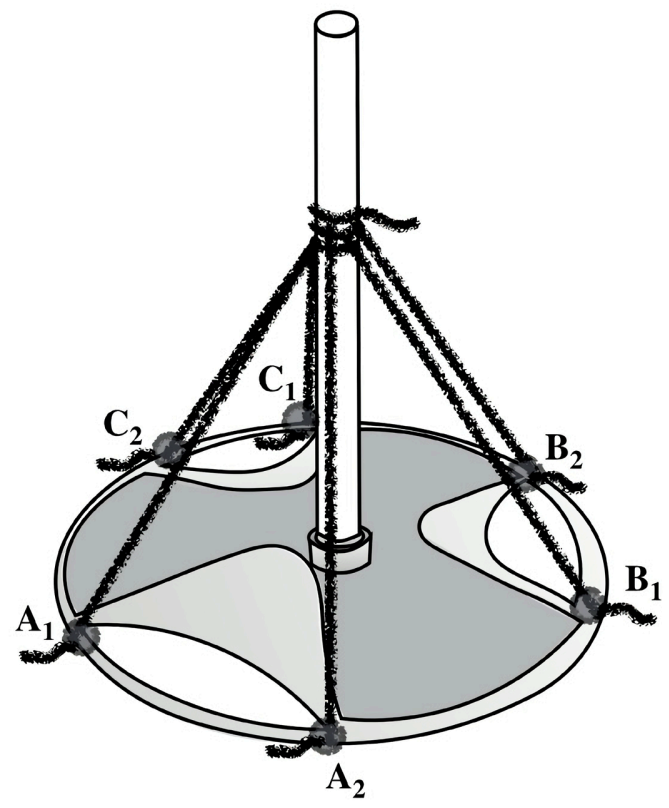

Figure 20. Tri-Lobed Disc reinforced by strings.

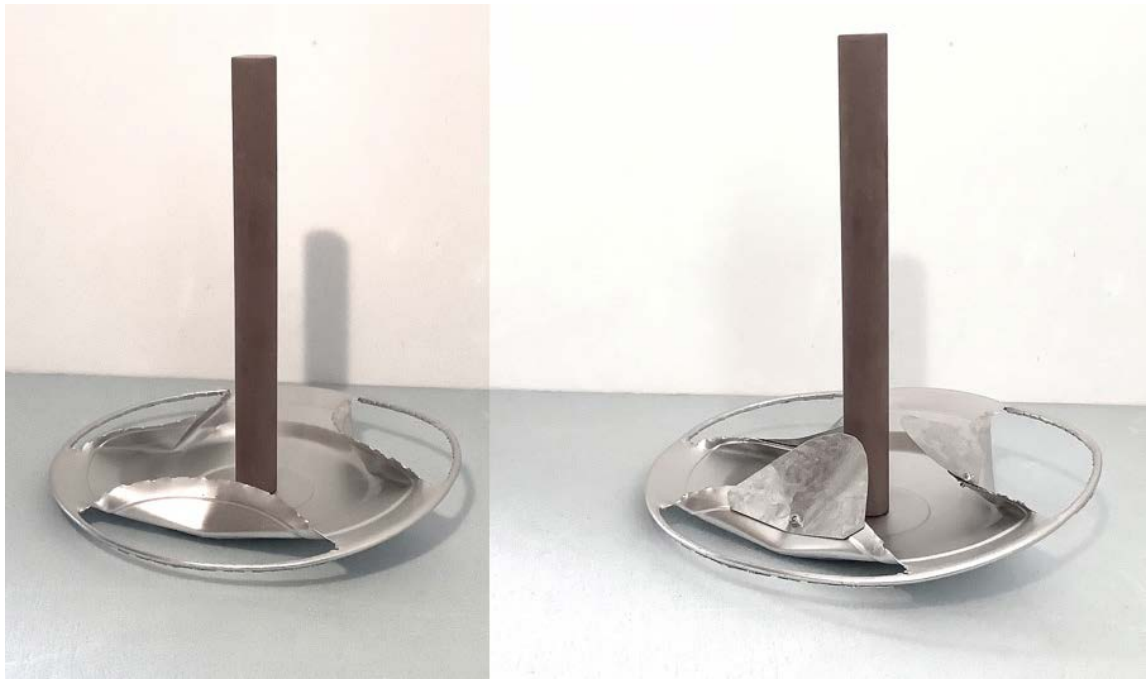

Figure 21. A model of Tri-Lobed Disc (right) made from an aluminium lid of cooking pot with diameter $28 \mathrm{~cm}$, by attaching fins (tinplates) to the short lobes of the model on the left.

1) At low Reynolds number, flow tends to be laminar, without turbulence.

2) When two vessels of same shape but of different sizes are moving in fluids, then the flow patterns around them are identical as long as they embrace the same Reynolds number (called the "Reynolds' Law of Similarity").

The Reynolds number Re defined by

$$
R e=\frac{V \cdot L}{v}
$$

is proportional to the moving speed $V$ and the "typical length" $L$ of the vessel, while inversely proportional to the "kinematic viscosity" $v$ of the fluid. The 
"typical length" of a disc can be its diameter. Suppose the Tri-Lobed Disc Figure 1 of the typical length $L_{0} \approx 60 \mathrm{~cm}$ moves at the speed $V_{0}$ in the wort of the kinematic viscosity $v_{0}$, while the metal disc Figure 21 of the typical length $L_{1} \approx 30 \mathrm{~cm}$ moves at the speed $V_{1}$ in the water of the kinematic viscosity $v_{1} \approx 1 \mathrm{cSt}$ where $\mathrm{cSt}=\mathrm{mm}^{2} / \mathrm{sec}$ denotes the centistoke. To apply the Law of Similarity, assume

$$
\frac{V_{0} \cdot L_{0}}{v_{0}}=\frac{V_{1} \cdot L_{1}}{v_{1}} \text {, then } V_{1} \approx\left(2 / v_{0}\right) V_{0} .
$$

This means that the flow pattern around the Tri-Lobed Disc Figure 1 moving at the speed $V_{0}$ in the wort can be realized in the experiment of the metal disc Figure 21 moving at the speed $V_{1} \approx\left(2 / v_{0}\right) V_{0}$ in the water, where $v_{0} \approx 2$ (roughly) in case the temperature of the wort is about $20^{\circ} \mathrm{C}$, while $v_{0} \approx 1$ around the temperature $60^{\circ} \mathrm{C}-70^{\circ} \mathrm{C}$ (the wort at high temperature is not so viscous); cf. (Hlaváč et al., 2016). Thus, in order to observe the flow pattern around the Tri-Lobed Disc, we just need to move the metal disc at the speed $V_{0}$ or $2 V_{0}$ in water.

\section{What We Expect as a Mash Tun for Prince Sabu}

We strongly believe that Prince Sabu had a "royal" mash tun big enough to accept the Tri-Lobed Disc. To imagine "how big it was," let us see some historical examples. The picture Figure 22 from the website of "Carling Brewery" shows mash tuns, both of which (on the left and on the right) are big enough to accept the Tri-Lobed Disc. A typical mash tun in medieval Europe can be seen in Figure 23 (Dineley, 2009), which is explained in (Dineley, 2010) that "the brick structure houses the metal container in which the crushed malt and water are mashed. A fire heats the mixture." Though this mash tun is not so big, we can easily think of its enlarged version. A big essential problem in the early Bronze
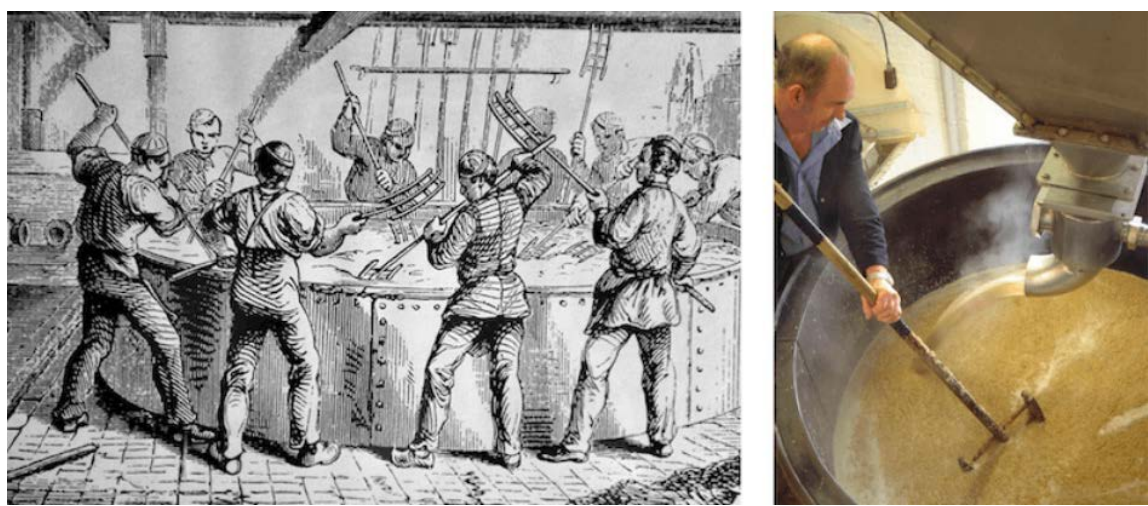

Figure 22. Examples of big mash tun: A picture taken from the website of "Carling Brewery" entitled "Brewing is more complex than wine making...", with the caption "Mashing by hand in days of yore. On the right is Batham's making sure everything is mixed in today."

(https://www.carlingpartnership.com/insights/brewing-is-more-complex-than-wine-mak ing/) 

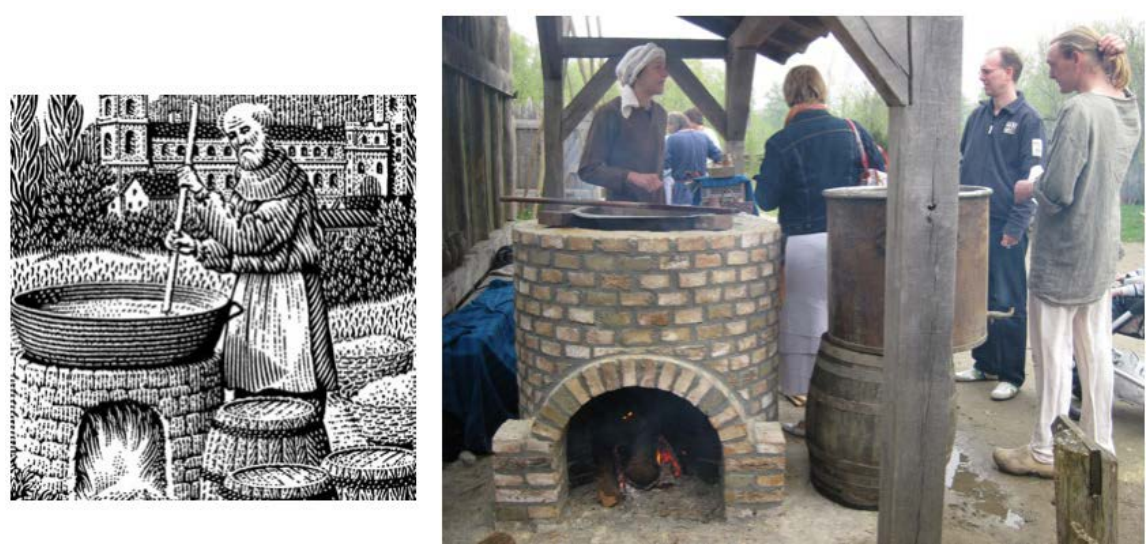

Figure 23. Medieval way of Mashing (Dineley, 2009). Brewers demonstrating medieval mashing techniques, as shown in the woodcut (left) of Monk brewing, at Eindhoven Open Air Museum, April 2009.

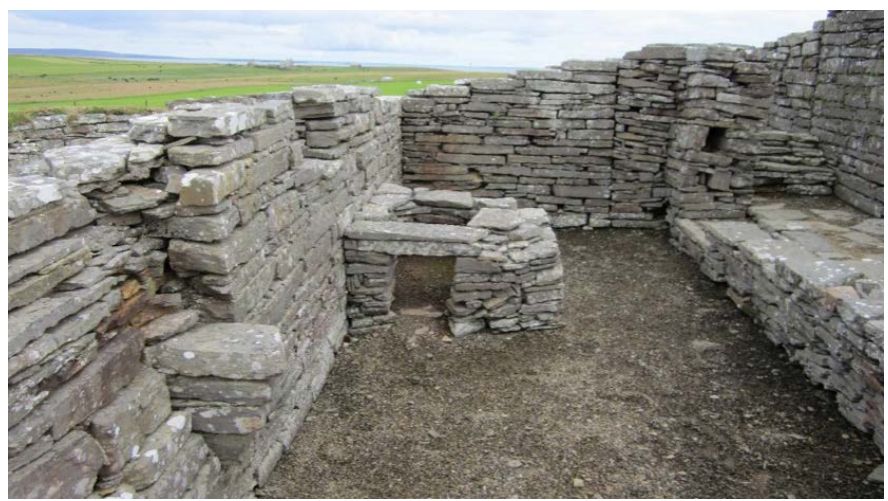

Figure 24. Mash oven, made of stones, in the Viking Brew Houses at Cubbie Roo's Castle (built around $1145 \mathrm{AC}$ ), on the island of Wyre, Orkney (Dineley \& Dineley, 2013).

Age of Prince Sabu would be that it was not easy to make a big "metal" container. So, we better expect that a mash tun around $3000 \mathrm{BC}$ would be made of mudbricks or stones. A historical example of mash oven made only of stones can be seen in Figure 24, which is an example in the Viking Age, at the Cubbie Roo's Castle on the island of Wyre, Orkney (Dineley \& Dineley, 2013). It is quite noteworthy that this facilities were previously excavated and interpreted as bath houses, but newly identified as brew facilities in the research (Dineley \& Dineley, 2013) by G. Dineley (a craft brewer) and M. Dineley (an archaeologist). This arises a question: Weren't there any mash tuns made of stone in ancient Egypt, previously excavated but misinterpretated? Yes, there were! As we show in the next section.

\section{Large Basins at the Sun Temple of Nyuserre}

In searching for any remains of ancient Egyptian mash tuns, we were hit by a new idea that the large basins at the sun temple of Nyuserre, Abu Ghurab, would be such ones. So, let us discuss here about this idea. The sun temple belongs to the Fifth Dynasty (2498-2345 BC), and in its open court Figure 25, we can see a total of 19 large basins: 9 alabaster basins Figure 26, Figure 27 (supposed to be 
10 , one is mssing), and 10 similar basins of limestone Figure 28. The function of these basins is not yet known: The discoverer Borchardt (Borchardt, 1905) claimed they were either to collect the blood of the victims which were sacrificed in the paved area, or the water used to clean the area itself after the sacrifice. But this interpretation had a serious weakness as pointed out in (Verner, 1994) that neither in the Great or Small "Slaughterhouse", nor anywhere else in the whole temple, has there been found any unmistakeable archaeological evidence of the killing of sacrificial animals. Furthermore, (Nuzzolo, 2016) showed that recent archaeological investigations at the site deny such interpretation and rather support the idea of (Eggebrecht, 1973) that the slaughtering activities did not fit the ritual purity of the temple according to the Egyptian mentality. Now, compare

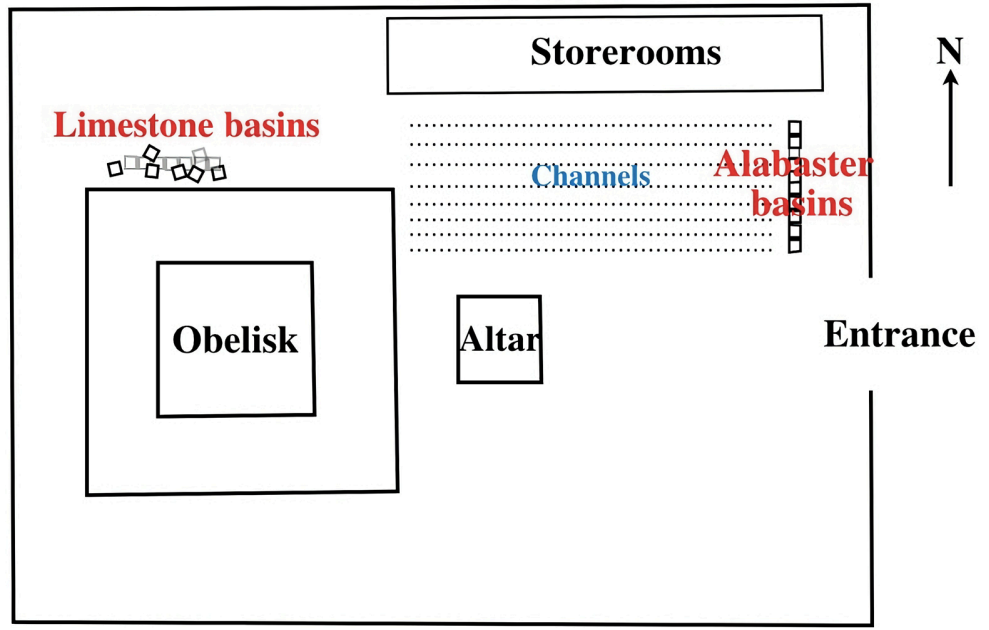

Figure 25. Outline of the open court of the sun temple. For details, see (Nuzzolo et al., 2018).

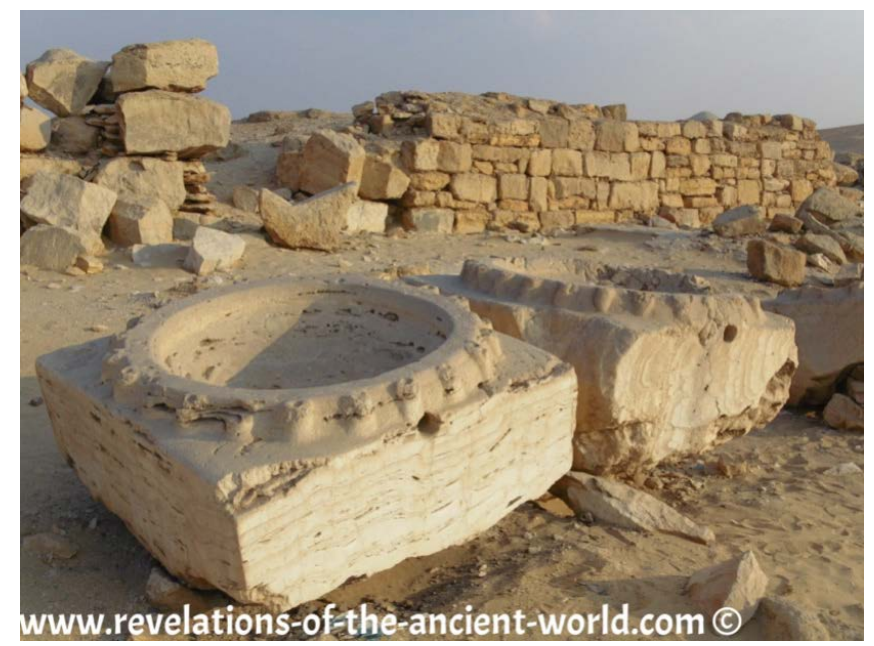

Figure 26. Large alabaster basins at Nyuserre's Sun Temple, Abu Ghurab, belonging to the Fifth Dynasty (2498-2345 BC)

(https://www.revelations-of-the-ancient-world.com/the-tanks-of-abu-ghorab/). Each has an inner circular bowl in the middle, with a diameter of about $120 \mathrm{~cm}$ and a depth of about $50 \mathrm{~cm}$. From the outside, it looks like a cuboid measuring $155 \mathrm{~cm}$ in width and 76 $\mathrm{cm}$ in height (Nuzzolo, 2016). 

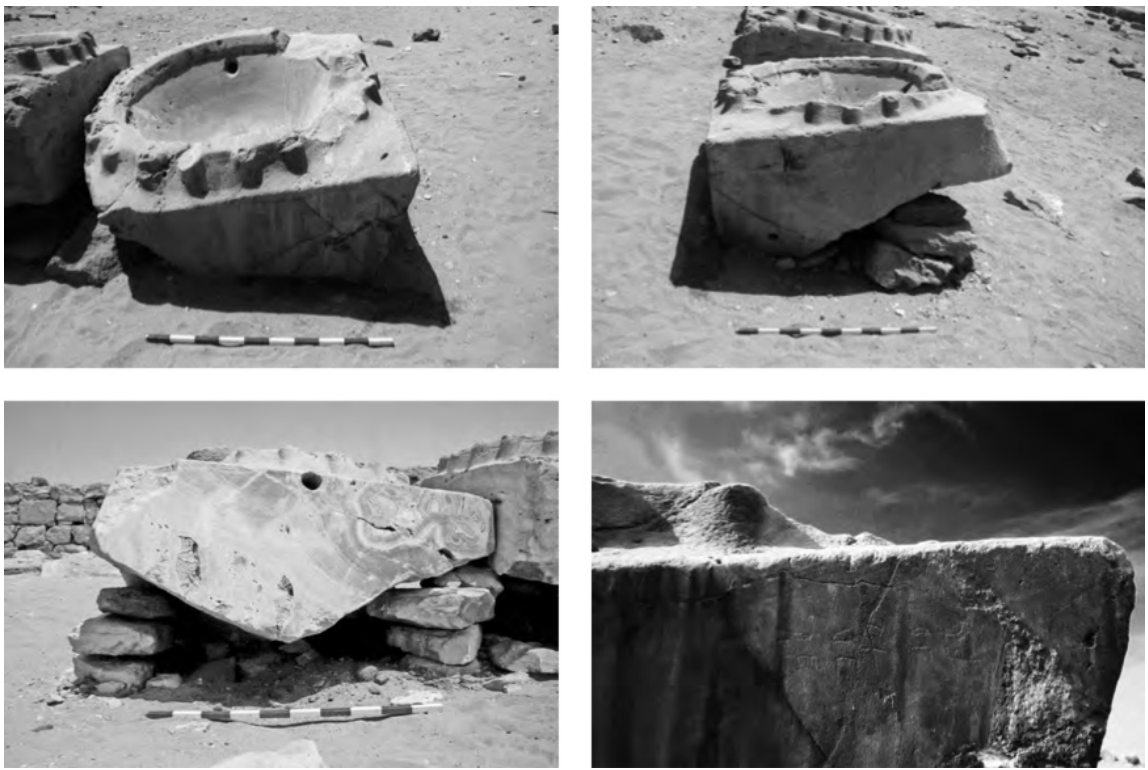

Figure 27. Detailed view of one of the alabaster basins at Nyuserre's Sun Temple. Seen from the eastern (top left), northern (top right) and western (bottom left) side, with detail of the inscription (bottom right). The basin has a horizontal hole or duct in its upper part, and rests on stones, not directly on the pavement (photos by M. Nuzzolo, (Nuzzolo, 2016)).

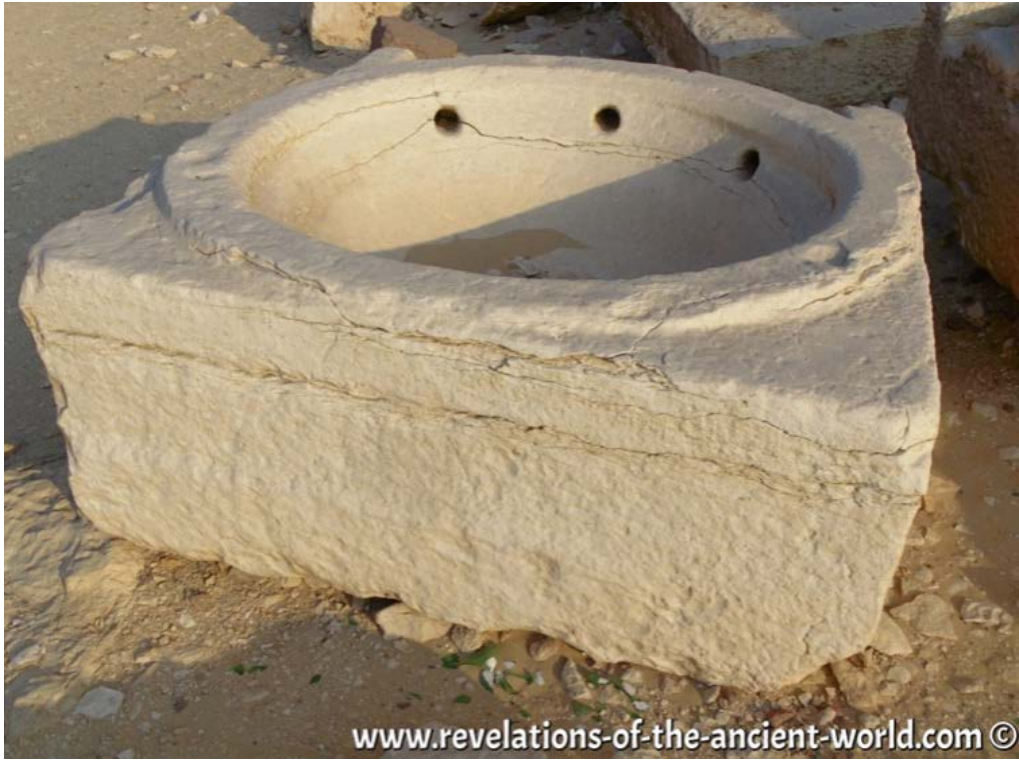

Figure 28. Limestone basin with three rounded holes or ducts, at Nyuserre's Sun Temple (https://www.revelations-of-the-ancient-world.com/the-tanks-of-abu-ghorab/).

the basins in the Fifth Dynasty (Figures 26-28) with the beer vats in the Predynastic era or the First Dynasty (Figure 7, Figure 8, Figure 10), regarding that those remains are almost entire vats, not the lower parts of some taller ones. Then one will notice the similarity in shape between them. Note also that the form of the inner circular bowls of the basins in the sun temple is similar to the bowl for mashing illustrated in the middle of the top row of the relief Figure 11 
of the beer-making process (Third Dynasty). Based on these similarities and taking account of the importance of beer as a sacred beverage offering to the gods, we naturally propose that:

The basins at the sun temple of Nyuserre were for beer brewing serving as mash tuns.

More precisely we can say that the basins were an improved, sophisticated version of the beer vats in the Predynastic era or the First Dynasty: Each vat of the latter is supported by a ring of mud wall or mudbrick fire-dogs (see Figure 29), while each basin of the former is made entirely of a stone forming a thick stone wall better for heating, than the wall of mud or mudbricks. In these basins a mixture of malted grain (probably, emmer wheat) and water was heated gently to make beer, and for this heating the basins rest on stones as seen in Figure 27, not directly on the pavement. Each alabaster basin has a horizontal hole or duct in its upper part (Figure 27), while each limestone basin has three such holes (Figure 28). We believe these horizontal ducts were used to pour the wort into jars. In addition to these structures, each alabaster basin has 26 very small round holes along its rim as can be seen in Figure 26, though no limestone one has such holes. About the role of these small holes we propose two feasible ideas. One is that jars with pointed base were placed on these small round holes with help of some devices. Such jars would be filled with the wort already made in the basin but still better to be warmed further. On the usual ground a jar with pointed base could be erected just by digging some hole (see Figure 29). But, making holes on the pavement of the open court where the basins are laid would not be easy, and better not to be done as such holes destroy the scenery of the court. So, it would be very convenient if jars can be placed on the rim of basin. But, how a jar could be erected on such a small hole? A simple subsidiary "device" would be "clay" as illustrated in Figure 30: Mound some clay on the rim of basin and make enlarged holes on the small holes to support jars. The clay would soon be dried to become like a mudbrick, and note that this clay structure need not be so strong since the weight of jars can be sustained almost by the small holes of the basin. The clay together with the erected jars would have made an additional wall in keeping the mash temperature up. Thus, as a whole, the basin

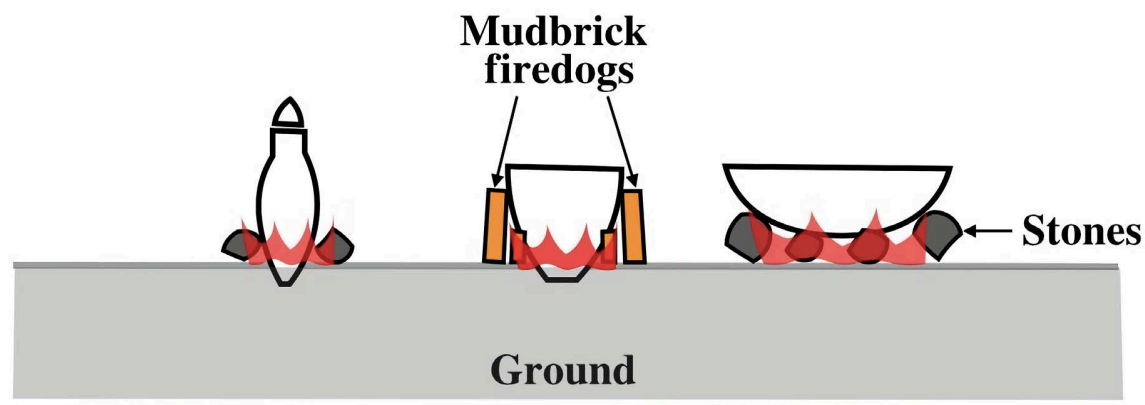

Figure 29. Various ways of heating, according to the shape of container: A jar with pointed base (left), a truncated conical bowl like the inner one of any vat in Figure 8 or Figure 10 (middle), and a bowl like the inner one of the basin in Figure 26 or Figure 28. 

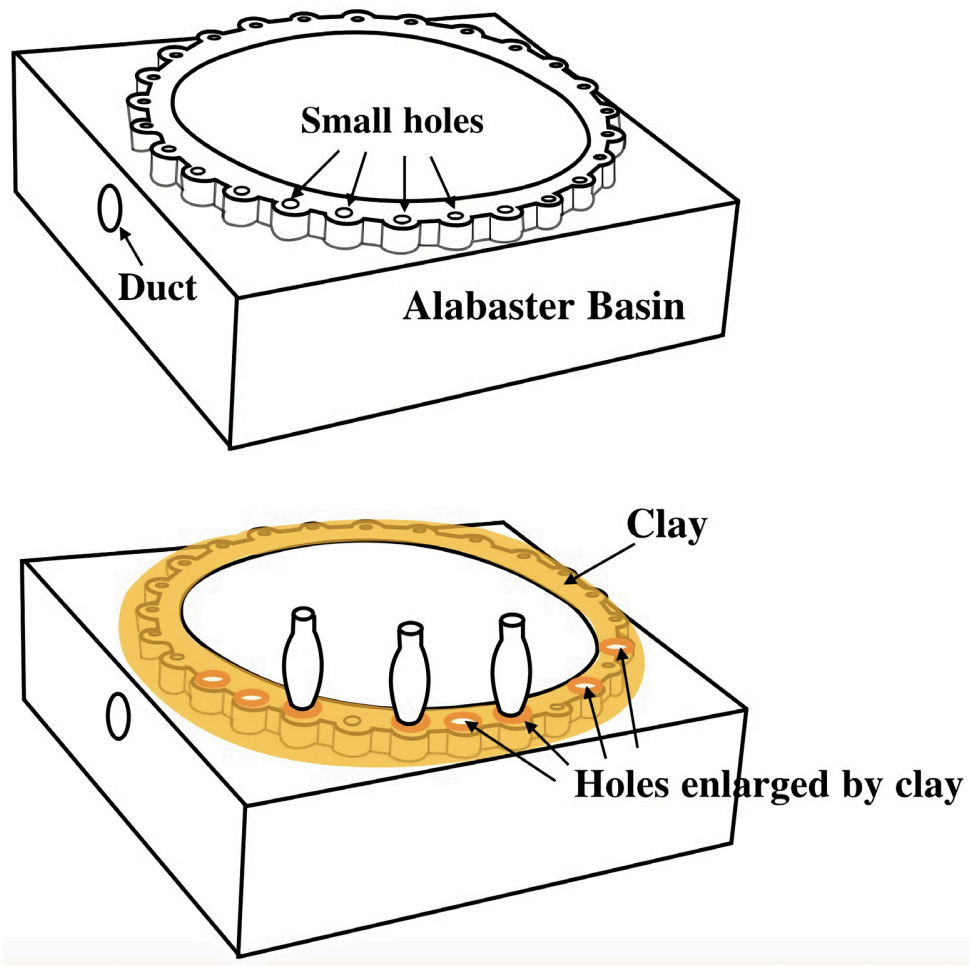

Figure 30. Beer jars with pointed base could be placed on the small round holes with help of clay.

could be used in the way as illustrated in Figure 31. Here, we also described a mash rake. Though such a mash rake could be a simple one, for example, like the one on the left of Figure 32, a more useful mash rake would be a half-sized version of the Tri-Lobed Disc (like Figure 21), which can serve also as a measure of grain like on the right of Figure 32 .

Another idea about the role of the small holes is related to the number of holes $26=13 \times 2$, which is close to $24=12 \times 2$. Recall that the number " 13 " was a preferable number for ancient Egyptians who believed that there were 12 stages to this life and the 13th was the ascension to an eternal afterlife. We believe the rim of the basin was used as a sundial. Though, of course, the obelisk stood high in the Court was surely used as a sundial, it would be very convenient if the basin itself could be used as a timekeeper. Let us explain how the basin can be a sundial. There would be three candidates for "gnomon" as in Figure 33: Vertical pole of a mash rake, beer jars on the rim of the basin, or verical poles touching the side face of the basin. Note that the mash rake here should be one with a slightly rounded bottom which fits well to the bottom of the inner bowl of the basin (as illustrated in Figure 33); then, the pole of the mash rake, placed at the center of the basin, will naturally stand vertical. Such a vertical pole can be the gnomon of the sundial as shown in Figure 33, Figure 34. An alternative way to make the basin into a sundial is to utilize the beer jars erected vertically on the rim of the basin as in Figure 30. They will make parallel shadows. Choose one of such shadows which directs to the center of the basin. Then, this shadow tells the 


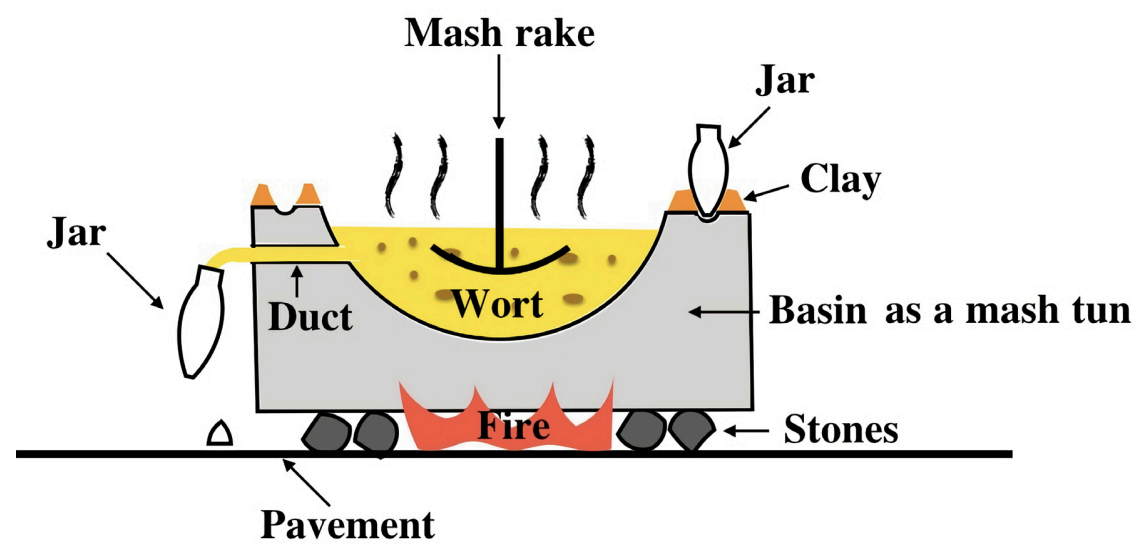

Figure 31. How the basin at the sun temple of Nyuserre was used.
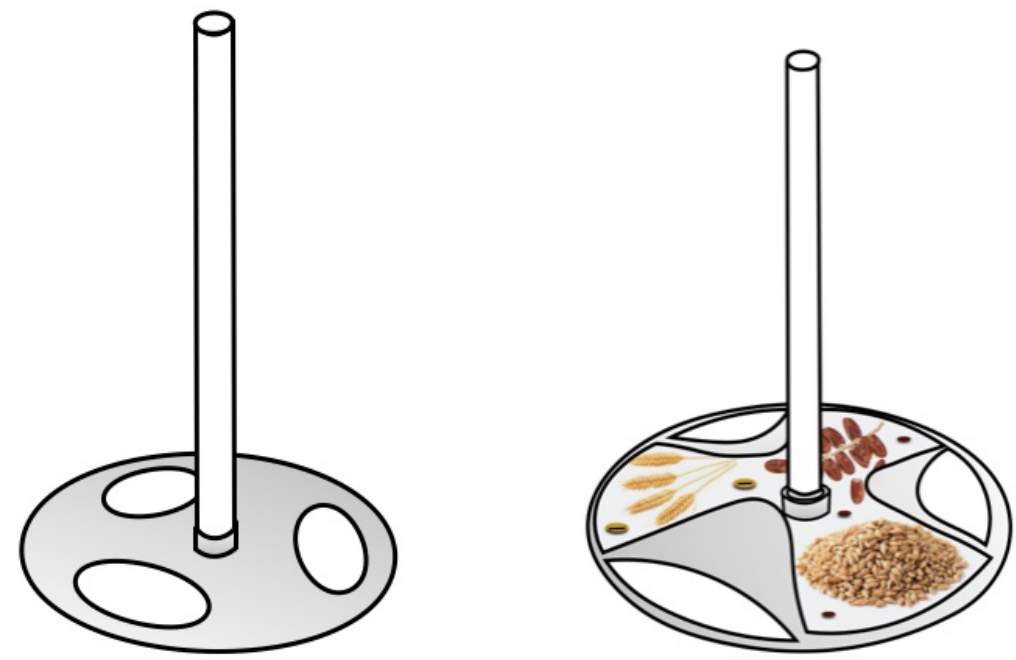

Figure 32. (Left): An example of simple mash rake, similar to the one in Figure 14. (Right): The rake of the form of the Tri-Lobed Disc can serve also as a measure of malted grain or additives (preservatives or flavours) to be added in the mash.

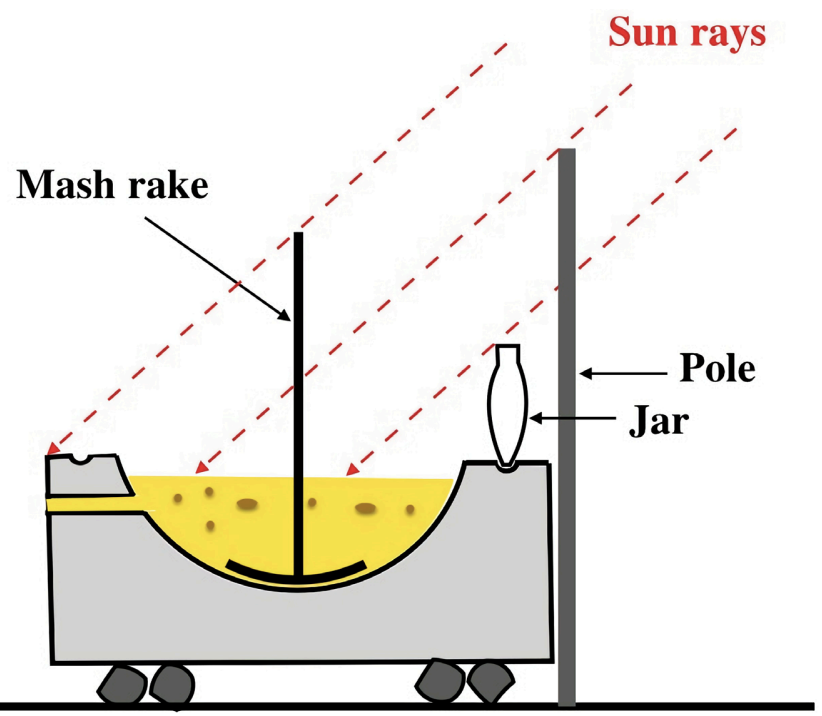

Figure 33. Three candidates for "gnomon": Mash rake, jar or pole. 


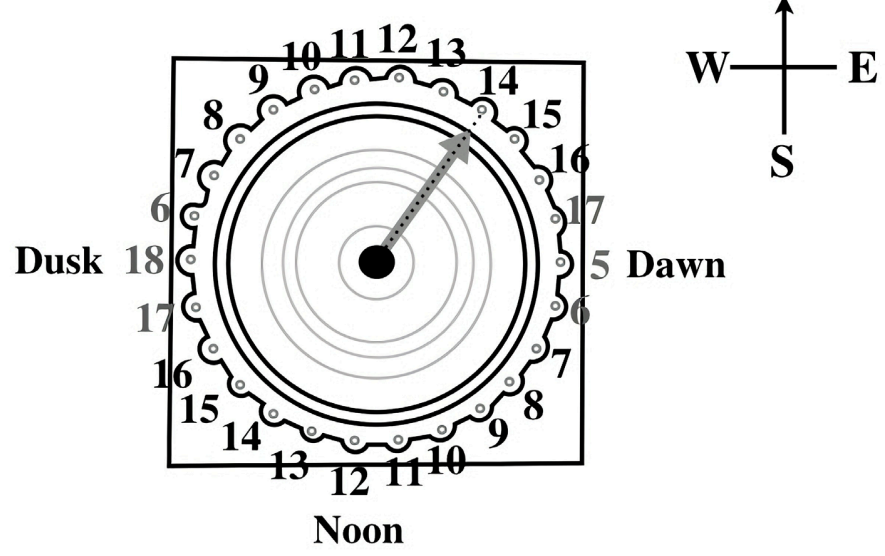

Figure 34. The sundial of the alabaster basin with the vertical pole of the mash rake as the gnomon, telling the time about 14:00 by its shadow (grey-colored arrow).

time. A typical instance of the use of this sundial would be like Figure 35: Suppose we have started mashing when the shadow of the jar A pointed the center of the basin, and want to check the state of wort about three hours later. What we need to do is to mark the jar B which is three intervals away leftwards from A, as on the left of Figure 35. Then the time "three hours later" would be when the shadow of the jar B points the center of the basin as on the right of Figure 35. In case we assume no jars on the rim, we can use vertical poles instead of jars as in Figure 36. Thus, in many ways, the basin can be a sundial. Note that this sundial would not be precise around the time of dawn or dusk, but that doesn't matter since the sundial would not be used around such time and mashing would be done in daylight. Since there are many basins, the starting time of mashing would differ among basins so that it would be quite helpful if each basin can tell the passing of time. It should be well noted that "measuring the passing time approximately" is more important than "knowing the present time accurately," so that the numbers on the dial as in Figure 34 need not be inscribed, and it does not matter even if the daytime was partitioned into 13 units, not 12 .

As mentioned before, the limestone basins have no small holes on their rims, and we have wondered what caused the difference of shape between the alabaster basin and the limestone one. As a feasible reason, we suspect either of the following:

1) Ten limestone basins were first set and used to serve beer, then in order to cope with the expansion of festivals at the sun temple, more beer was needed to be produced so that ten alabaster basins were further set. So, the alabaster basin is an improved sophisticated version of the limestone one.

Or: 2) All basins were used for the "brew in two-part process" as described in (Adamski, \& Rosińska-Balik, 2014) so that the whole cereal was divided into two portions, one batch was to make the uncooked malt in the limestone basins while other batch was to produce the well cooked grain in the alabaster basins, and later, these two portions were mixed together in the alabaster basins. So, the difference 


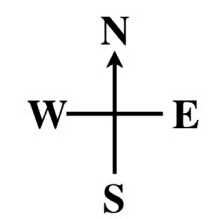

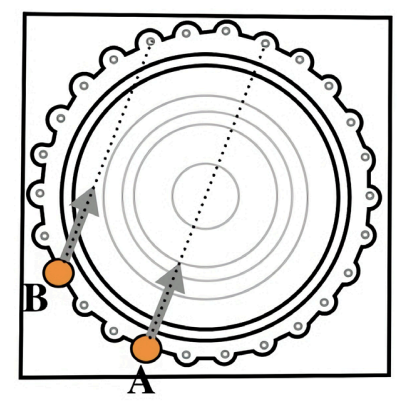

State A

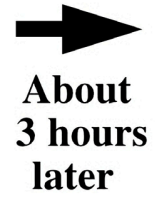

later

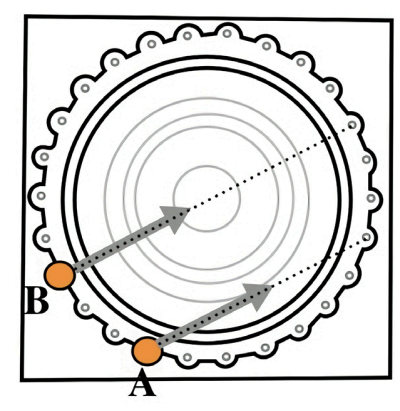

State B

Figure 35. In State A (resp. B) the shadow of the jar A (resp. B) directs to the center of the basin. Passage of time from State A to State B can be read as about 3 hours by counting the 3 intervals between $\mathrm{A}$ and $\mathrm{B}$.

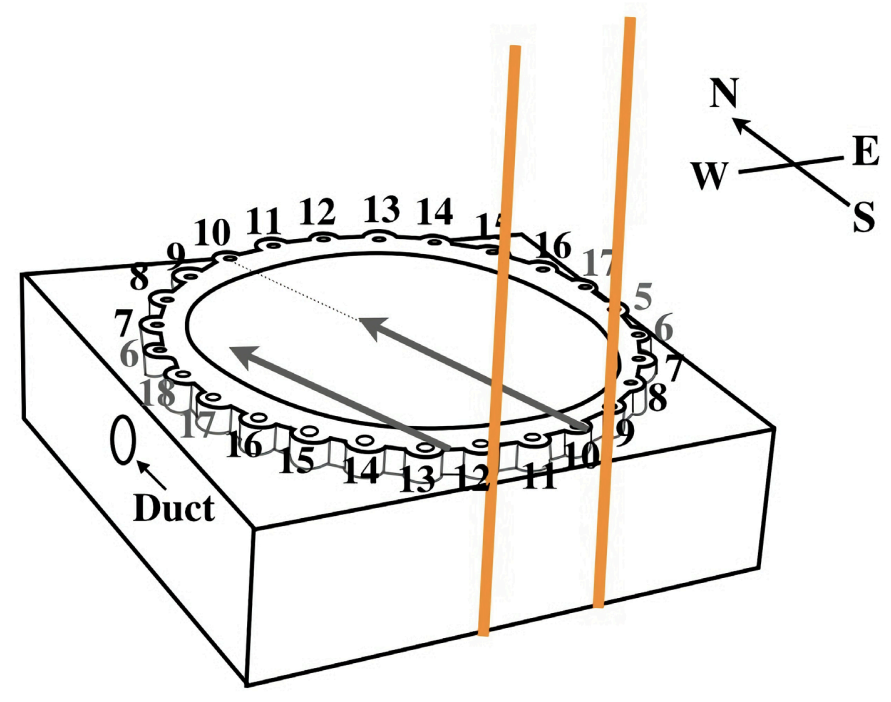

About 10 : 00

Figure 36. Verical poles touching the side face of the basin can be used to measure time, instead of jars on the rim.

of shape of basins was due to the difference of role. This two-part process was already adopted at both of the Hierakonpolis and Abydos breweries, and the vats there were found to be arranged in two parallel rows (Adamski, \& Rosińska-Balik, 2014). But we note the arrangement of basins (assuming they were in situ) in the sun temple is not parallel, as can be seen in Figure 25: the alabaster basins on the north-eastern side of the sun temple are aligned along the north-south axis, while the limestone ones in the north-western sector look aligned along the east-west axis. 

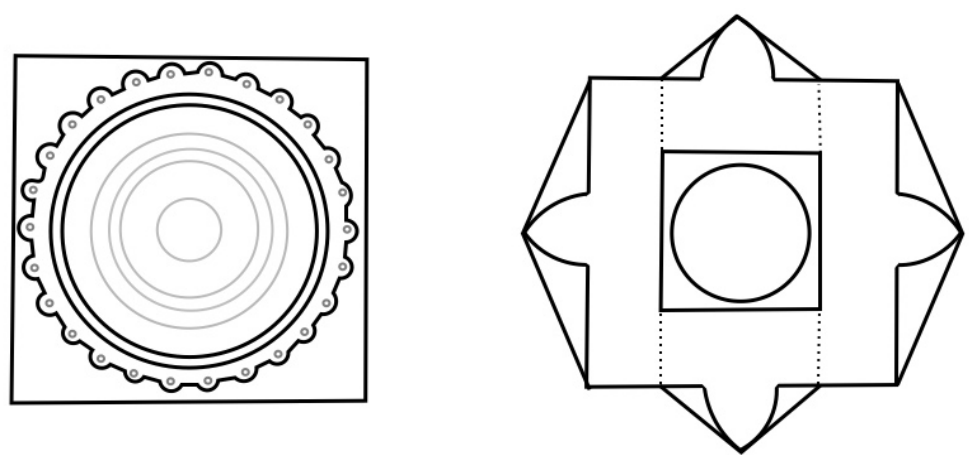

Figure 37. Top view of the alabaster basin (left) and the altar, both symbolizing the sun with the corona. Their common feature is "a disc in a square with flares."

About the shape of basins, it would be quite natural to reason that since the sun temple was built to honor the sun god $\mathrm{Ra}$, the basins as well as the altar in the center of the Court were designed to symbolize the sun. All of them have the common feature of "a disc in a square," and an additional feature of the sun flare "corona" can be seen in the alabaster basins and the altar: See Figure 37. The heated basin filled with warm brown-colored wort is nothing but the sun!

Anyway, the presence of so many large basins indicates that the sun temple was so dignified and distinguished to perform big religious celebrations to consume beer in great quantities, so that the storerooms (or "storage magazines") adjacent to the alabaster basins, located to the right of the entrance of the temple Figure 25, were always filled with lots of the main offering material, i.e., beer jars.

Addendum to Section 4: Now we can imagine that a would-be "royal" mash tun for Prince Sabu was probably like an enlarged version of the alabaster or limestone basin in the Sun Temple, made of mudbricks or stones.

\section{Concluding Remarks}

We have proposed that the Tri-Lobed Disc was a mash rake to mix and even-out the mixture of grains and hot water in a fairly big beer brewing mash tun, and we believe that its sophisticated function well improved the wort quality. The reasons which support our idea can be summarized as follows:

1) The curvature of the Disc with the slightly round base and smoothly curved lobes suggests its usage in some liquid.

2) The Disc should be moved in the liquid softly, not abruptly since it is made of the material not so strong. Then, the smoothly curved lobes can turn the liquid along their curved surfaces.

3) Almost all of the votive objects in the burial chamber of Prince Sabu are related to "foods" for the afterlife of Prince Sabu so that it is natural to assume the Disc was for beer, an essential provision for the afterlife.

4) The color of the Disc was chosen to be grey in order to be well contrasted to the brown color of the wort, making easy to examine the state of wort. 
Assuming our theory, we can even assert as follows: The fact that such an elaborate delicate mash rake was actually made and was placed as a votive object at the center of the burial chamber of Prince Sabu indicates that the importance of mashing in the brewing process was well recognized in the long history of Egyptian brewing.

In literatures we can find various ideas about possible usage for the Tri-Lobed Disc; cf. (Solenhofen, 2003). The discoverer Emery himself described it as a metasiltstone "bowl" as noted in Figure 4. An English engineer, William Kay, has suggested that the vessel was a ritualistic tri-flamed oil lamp, in which bundles of rushes, immersed in oil, acted as the wicks (s8int, 2020). (Hassaan, 2016) suggests, as a mechanical engineer, that this unit may be a rotor for a certain type of centrifugal pumps. Among others, (Vashakidze, 2016) claimed that the Disc was used as a steam machine to distribute water vapor in the air efficiently and rapidly, like a sauna; and this idea is close to ours in the sense that he considered "mixing the gas, water vapor, in a room like sauna," while we have considered "mixing the liquid, wort, in a mash tun."

As a by-product of this research, we also uncovered or reinterpretated the role of the basins at the sun temple as mash tuns for ritual beer brewing. The authors of (Dineley \& Dineley, 2013), one of whom is a craft brewer, assert that "the brewer requires a good floor to accommodate sticky and messy spillages, paving would be ideal and good drains are essential." The sun temple well satisfies these conditions as described in (Nuzzolo, 2016) that: The area of the so-called "big slaughterhouse," located in the north-eastern sector of the sun temple, is characterized by a limestone pavement inset with channels, each $24 \mathrm{~cm}$ wide. Note also the report in (Arias, 2020) that "A large amount of ceramic finds (most of which belong to the Fifth Dynasty) came from the cleaning of the area of the alabaster basins. ... Among the contexts, jars were the most frequent class, with a clear predominance of beer jars in both diagnostic and non-diagnostic sherds, followed by the class of bread forms in diverse types." While looking around the area of the limestone basins, Brien Foerster pointed out in his video (2017)

(https://www.megalithicbuilders.com/africa/egypt/lower-egypt/abu-gorab-sun-t emples) that "some of the stones appear to have scorch or heat marks." This observation surely supports our idea that the basins were heated for brewing. Thus, we want to conclude this article with our hope that, in near future, any brewing residues on and around the basins would be detected further to be examined chemically, in order to confirm our view, together with scorch on the basins as an evidence of heated mashing. As mentioned at the end of Section 1, we insist that the importance of ritual brewing should be taken seriously in the history of ancient Egypt, in particular in the third and fourth millennia BC. A bit amazingly, this is true even outside of Egypt: (Dineley, 1997) claims about the Neolithic culture around Orkney, Scotland, that "Ritual brewing may have been one of the main activities that took place at sacred Neolithic ceremonies in the 3rd millennium BC." 


\section{Conflicts of Interest}

The author declares no conflicts of interest regarding the publication of this paper.

\section{References}

Adamski, B., \& Rosińska-Balik, K. (2014). Brewing Technology in Early Egypt. Invention of Upper or Lower Egyptians? In A. Mączyńska (Ed.), The Nile Delta as a Centre of Cultural Interactions between Upper Egypt and the Souther Levant in the 4th Millennium $B C$ (pp. 23-36). Studies in African Archaeology Vol. 13, Poznan Archaeological Museum.

Arias, K. (2020). Survey, Study and Documentations of the Pottery. Newsletter Archeologia CISA, 11, 299-301.

Bond, S. E. (2021). Discovery of an Industrial Brewery in Ancient Egypt Rewrites the History of Beer.

https://hyperallergic.com/629493/discovery-of-an-industrial-brewery-in-ancient-egypt -rewrites-the-history-of-beer

Borchardt, L. (1905). Das Re-Heiligtum des Königs Ne-woser-re (Rathures), Bd. 1. Der Bau. Duncker.

Dineley, G., \& Dineley, M. (2013). Where Were the Viking Brew Houses? EXARC Journal, No. 2013/2. https://exarc.net/ark:/88735/10117

Dineley, M. (1997). Beer Brewing Formed Part of Neolithic Ceremonies. British Archaeology, News, Issue 27.

https://www.academia.edu/209779/Beer brewing formed part of Neolithic ceremon ies

Dineley, M. (2009). Bread, Beer or Something Else? A Science Based Perspective on the Neolithic and the Origin of Grain Agriculture Debate. Eindhoven Open Air Museum. https://www.academia.edu/1662198

Dineley, M. (2010). Experiment or Demonstration? Making Fermentable Malt Sugars from the Grain and a Discussion of Some of the Evidence for This Activity in the British Neolithic. In D. C. E. Millson (Ed.), Experimentation and Interpretation: the Use of Experimental Archaeology in the Study of the Past (pp. 96-108). Oxbow Books.

Eggebrecht, A. (1973). Schlachtungsbr äuche im Alten Ägypten und ihre Wiedergrabe im Flachbild bis zum Ende des Mittleren Reiches. Unpublished Ph.D. Thesis, Ludwig Maximilians Universität.

Emery, W. B. (1949). Great Tombs of the First Dynasty, Vol. 1, Excavations at Saqqara, Service des Antiquités de I'Egypte. Government Press.

Farag, M. A., Elmassry, M. M., Baba, M., \& Friedman, R. (2019). Revealing the Constituents of Egypt's Oldest Beer Using Infrared and Mass Spectrometry. Scientific Reports, 9, Article No. 16199. https://doi.org/10.1038/s41598-019-52877-0

Friedman, R. (2011). Hierakonpolis. In E. Teeter (Ed.), Before the Pyramids the Origins of Egyptian Civilization (pp. 33-44). Oriental Institute Museum Publications 33, The University of Chicago.

Geller, J. R. (1992). Predynastic Beer Production at Hierakonpolis, Upper Egypt: Archaeological Evidence and Anthropological Implications. Ph.D. Dissertation, Washington University, University Microfilms.

Hassaan, G. A. (2016). Mechanical Engineering in Ancient Egypt, Part XIII: Stone Vessels (Predynastic to Old Kingdom Periods). International Journal of Recent Engineering 
Science (IJRES), 19, 14-24.

Hlaváč, P., Božiková, M., \& Cviklovič, V. (2016). Dynamic Viscosity and Activation Energy of Wort during Fermentation and Storing. Acta Technologica Agriculturae, 1, 6-9. https://doi.org/10.1515/ata-2016-0002

Luoma, E. (2009). Egyptian Brewing: The Production of Beer Based on Archaeological Evidence. Thesis for Master of Arts in Archaeological Studies, Univ. of Wisconsin-La Crosse. http://digital.library.wisc.edu/1793/38042

Nuzzolo, M. (2016). An Enigmatic Graffito from the Sun Temple of Nyuserre and the Meaning of the So-Called "Slaughterhouse. Prague Egyptological Studies, 17, 52-66.

Nuzzolo, M., Pirelli, R., Zanfagna, P., D’Andrea, A., Bosco, A., Osman, M., Krejčí, J., \& Brienza, E. (2018). Sun Temple of Nyuserre in Abu Ghurab: Report of the 2017 Season. Prague Egyptological Studies, 21, 45-72.

s8int (2020). The Mysterious Egyptian Tri-Lobed Disc.

https://s8int.com/2020/02/21/the-mysterious-egyptian-tri-lobed-disc

Solenhofen, A. (2003). The Tomb of Sabu and the Tri-Lobed "Schist" Bowl. https://www.bibliotecapleyades.net/egipto/esp egipto mist 2c.htm

Vashakidze, G. (2016). Disc of Sabu-Steam Machine (Ancient Egyptian Techniques). http://sciencegiz.com/images/bookpdf/Gizo-Vashakidze--Disk-of-SABU.pdf

Verner, M. (1994). Forgotten Pharaohs Lost Pyramids: Abusir. Academia Škodaexport.

\section{Appendix}

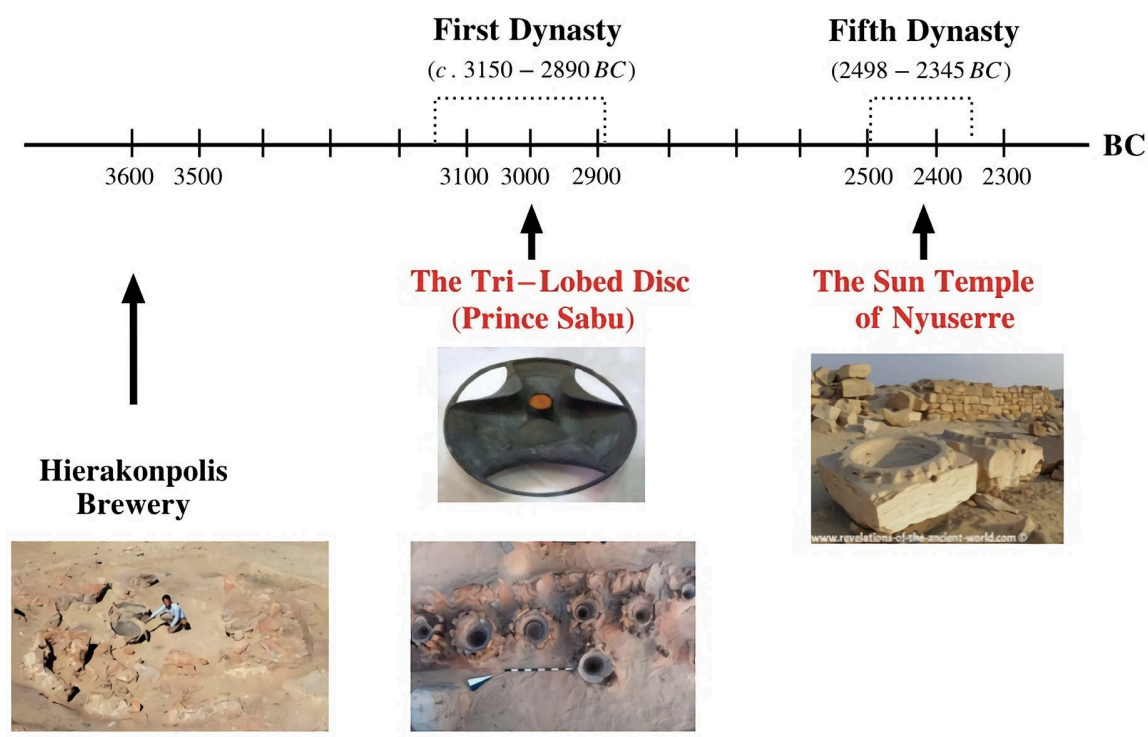

Abydos Brewery

Figure A1. Chronicle relating to this article, around $3000 \mathrm{BC}$. 